\title{
Experimental study of aluminium lipped channel sections subjected to web crippling under
}

\author{
two flange load cases
}

\author{
Mr Husam Alsanat
}

School of Engineering and Built Environment, Griffith University

Gold Coast, Australia. husam.alsanat@griffithuni.edu.au

Dr Shanmuganathan Gunalan

School of Engineering and Built Environment, Griffith University

Nathan, Australia.s.gunalan@griffith.edu.au

\section{Professor Hong Guan}

School of Engineering and Built Environment, Griffith University

Gold Coast, Australia.h.guan@griffith.edu.au

\section{Dr Poologanathan Keerthan}

Faculty of Engineering \& Environment, Northumbria University

Newcastle, UK. keerthan.poologanathan@northumbria.ac.uk

\section{Professor John Bull}

Faculty of Engineering \& Environment, Northumbria University

Newcastle, UK. john.w.bull@northumbria.ac.uk

\begin{abstract}
The application of aluminium alloy members in building construction has considerably increased in recent years due to their appealing advantages such as corrosion resistance and high strength-to-weight ratio. However, the elastic modulus of aluminium is only one third of that of steel, making aluminium members being susceptible to various buckling modes including web crippling. To date, only a limited amount of research study has been conducted to investigate the web crippling failure phenomenon in aluminium structural members, and no research has been carried out on the web crippling behaviour of roll-formed aluminium lipped channel sections. Hence, an experimental study was conducted to assess the web crippling behaviour and capacities of unfastened aluminium lipped channel sections under two flange load cases (EndTwo-Flange (ETF) and Interior-Two-Flange (ITF)). Forty tests were performed with different bearing lengths, web heights and thicknesses. The results obtained from this study were then compared with the nominal web crippling strengths predicted using the design rules provided by the Australian, European and American Standards. The comparison showed that the current design equations are potentially unsafe and unreliable to estimate the capacity for aluminium lipped channel sections under both ETF and ITF load cases. Hence, suitable modifications were proposed to the available design equations based on the experimental results to accurately predict the web crippling capacities of aluminium lipped channel sections. Generally, it is shown that the web crippling results acquired from the modified equations agreed well with the test results.
\end{abstract}

Key words: aluminium lipped channel sections; web crippling; two flange load cases; experimental study; design rules 


\begin{tabular}{|c|c|}
\hline$b_{f}$ & flange width \\
\hline C & web crippling coefficient \\
\hline$C_{f}$ & yield stress coefficient \\
\hline$C_{h}$ & web slenderness coefficient \\
\hline$C_{n}$ & correction factor depending on the number of tests \\
\hline$C_{N}$ & bearing length coefficient \\
\hline$C_{R}$ & inside corner radius coefficient \\
\hline$d$ & web (total) height \\
\hline$d_{w}$ & web height between flange mid-lines \\
\hline$E$ & Young’s modulus of elasticity \\
\hline$F_{m}$ & mean value of fabrication factor \\
\hline$f_{y}$ & yield stress \\
\hline$h$ & web (flat) height \\
\hline$k_{y}$ & the yield strength factor \\
\hline$L$ & specimen length \\
\hline$l_{b}$ & lip length \\
\hline$M_{m}$ & mean value of material factor \\
\hline$n$ & number of tests \\
\hline$N$ & load bearing length \\
\hline$P_{A S 1664}$ & ultimate load obtained from Eqs. (1 and 2) \\
\hline$P_{A S 1664(\text { prop. })}$ & ultimate load obtained from Eqs. (8 and 9) \\
\hline$P_{A S 4600}$ & ultimate load obtained from Eq. (4a) \\
\hline$P_{E C 3}$ & ultimate load obtained from Eqs. (5 and 6) \\
\hline$P_{E C 3(\text { Prop.) }}$ & ultimate load obtained from Eqs. (10 and 11) \\
\hline$P_{E C 9}$ & ultimate load obtained from Eq. (3) \\
\hline$P_{\text {Exp. }}$ & ultimate load obtained from experimental test \\
\hline$P_{\text {LAVAN }}$ & ultimate load obtained from Eq. (4b) \\
\hline$P_{m}$ & mean value of tested-to-predicted load ratio \\
\hline Predicted & ultimate load obtained from equation \\
\hline Prop. & ultimate load obtained from Eq. (7) \\
\hline$r_{i}$ & inside corner radius \\
\hline $\mathrm{t}$ & thickness \\
\hline$V_{F}$ & coefficient of variation of fabrication factor \\
\hline$V_{m}$ & coefficient of variation of material factor \\
\hline$V_{P}$ & coefficient of variation of tested-to-predicted load ratio \\
\hline$V_{Q}$ & coefficient of variation of load effect \\
\hline$\propto$ & coefficient for various local loads and support categories \\
\hline$\beta_{0}$ & reliability index \\
\hline$\varepsilon_{u}$ & elongation (tensile strain) at fracture \\
\hline$\sigma_{u}$ & static ultimate tensile strength \\
\hline$\sigma_{0.2}$ & static $0.2 \%$ proof stress \\
\hline$\theta$ & angle between the plane of web and the plane of bearing surface \\
\hline$\phi_{w}$ & resistance (capacity) factor \\
\hline$\gamma_{M 1}$ & partial safety factor \\
\hline
\end{tabular}

\section{Introduction}

During recent decades, the use of aluminium alloys in construction industries has prominently increased due to the growing demand for sustainable structural performance. Possessing properties like high strength-toweight ratio, corrosion resistance, recyclability, and low maintenance make aluminium structures cost and energy efficient. Moreover, aluminium proves to be more favourable than other materials in their entire life 
cycle, regardless of high energy consumption and cost during production [1-3]. From design perspective, aluminium alloys can be made available with high strength, within the range of steel. However, the relatively low elastic modulus of aluminium material makes aluminium members more susceptible to various kinds of instabilities including web crippling.

In construction, aluminium as a load carrying element is becoming increasingly popular in a wide range of structural applications, from conventional structural applications including joists, rafters, purlins and columns [4] to innovative applications such as passive energy dissipation devices for seismic protection in framed buildings [5]. Figure 1 (a) shows the structural application of aluminium lipped channel members as purlins in the Caloundra potable water reservoir, Australia, while Figure 1 (b) shows the lipped channel section profile. Similar to cold-formed steel members, unstiffened roll-formed aluminium joists and bearers may experience localised web crippling failure due to high transverse concentrated forces applied over a short length of the beam. The web crippling failure modes of a beam can be different according to the loading locations such as end columns, interior columns and joists supported by bearers. For example when an aluminium rafter supported by columns from the bottom and highly loaded by a purlin from the top may induce web crippling failure. Depends on the locations of the loads and supports, four failure scenarios can be potentially occurred according to the AISI Standard test method [6], namely End-One-Flange (EOF), InteriorOne-Flange (IOF), End-Two-Flange (ETF), and Interior-Two-Flange (ITF) load cases.

The aims of this research are to investigate the web crippling strengths and behaviour of aluminium lipped channel sections under the ETF and ITF load cases, and evaluate the accuracy and the reliability of the current design rules. Test setup and specimen lengths were selected according to the AISI Standard test method [6]. The web crippling strengths acquired from the tests were compared with the predicted web crippling capacities using the currently available design rules including AS/NZS 1664.1 [7], AA Specification [8], AS/NZS 4600 [9] and AISI S100 [10] and Eurocode 3 [11]. Subsequently, suitable amendments were made to improve the accuracy of these equations and to produce accurate predictions of the web crippling capacity for aluminium lipped channel sections. It should be noted that the design rules for aluminium structures in AS/NZS 1664.1 [7] are identical to those in AA Specification [8], and hence only AS/NZS 1664.1 [7] is discussed in this paper. Similarly the design rules for cold-formed steel structures in AS/NZS 4600 [9] are identical to those in AISI S100 [10], and hence only AS/NZS 4600 [10] is discussed in this paper.

\section{Previous studies on web crippling}

Literature review shows that a considerable amount of experimental research has been conducted to investigate the web crippling failure phenomenon in structural members. Most of these studies were focused on coldformed steel members with only few of them being performed using aluminium members. 


\subsection{Cold-formed steel sections}

Since 1940s, extensive testing of different cold-formed steel sections such as Z-, C- and hat sections as well as built up sections has been undertaken in order to develop empirical design rules to predict the web crippling capacity. The web crippling capacities of cold-formed steel sections under different load cases were investigated in the past [12-23] using different section types, material strengths and bearing lengths.

Recently Gunalan and Mahendran [24] investigated the web crippling capacities of DuraGal sections (unlipped channel) subjected to two flange (ETF and ITF) load cases using unfastened bearing plates. The results were compared with the currently available design rules to investigate their suitability and new equations were proposed to predict the web crippling capacities of channel sections. Sundararajah et al. [25, 26] conducted a series of tests of lipped channel beams (LCBs) under two flange load cases and proposed an improved equation to determine the web crippling capacities of LCBs. The equation uses the same technique as of AS/NZS 4600 [9] with introduction of a new factor accounting for the effect of yield stress. Furthermore, Sundararajah et al. [27] performed experimental study on innovative SupaCee sections with longitudinal web stiffeners under two flange load cases. New coefficients were proposed with the web crippling design rule in the AS/NZS 4600 [9] standard to predict their capacities.

Keerthan et al. [28], and Steau et al. [29, 30] investigated the web crippling behaviour and capacity of hollow flange channel beams under ETF and ITF load cases. The test results showed that the predictions from the current design equation in AS/NZS 4600 [9] are either over-conservative or unconservative and hence new proposed equations were presented to estimate the web crippling capacity of hollow flange channel beams.

\subsection{Aluminium sections}

Tryland et al. [31] conducted web crippling tests using aluminium beams with three different extruded sections (two square hollow sections with different wall thicknesses and a double T section) fabricated by AA6082-T6 aluminium alloy. However, the minimum lengths as specified in the AISI Standard test method [6] were not considered in this study.

Zhou and Young [32] and Young and Zhou [33] performed a series of tests using square and rectangular hollow sections subjected to web crippling under the ETF and ITF load cases. The sections were fabricated using 6061-T6 and 6063-T5 heat- treated aluminium alloys. The results were compared with the current design rules given by AS/NZS 1664.1 [7], Eurocode 9 [34] and AS/NZS 4600 [9]. This study found that the design strengths predicted by the aforementioned specifications were either over-conservative or unconservative, and the predictions were in general unreliable. Thus, two unified web crippling equations for aluminium square and rectangular hollow sections were proposed under ETF and ITF load cases. Zhou and Young [35] also conducted a series of tests under end and interior one flange load cases using high-strength extruded hollow 
sections fabricated by 6061-T6 aluminium alloy. The support condition of the specimens closely resembled that of the joist members seated on a solid foundation in the floor system.

Recently, Chen et al. [36] carried out an investigation on web crippling failure of extruded aluminium tubular sections to propose improved design rules. Specimens with different boundary conditions, section heights and bearing lengths were tested. They also investigated the effects of these variables on the web crippling ultimate capacity and the ductility of aluminium square hollow sections. Su and Young [37] performed experimental and numerical web crippling investigations on relatively stocky hollow sections under the four load cases. The specimens were extruded using 6063-T5 and 6061-T6 heat treated aluminium alloys. The acquired results were used to assess the currently available design rules and new equations were proposed with the consideration of strain hardening effects.

It should be mentioned that majority of the existing experimental studies on aluminium members were focused on extruded sections, particularly rectangular hollow sections. However, the design guidelines resulted from these studies may not be applicable to roll-formed aluminium sections including channel sections. This is due to the nature of roll-forming fabrication, which involves continuous bending to a strip of sheet metal to achieve the desired shape, and consequently leads to a remarkable change to the material properties. Another reason is that hollow sections (SHS/RHS) are considered as multi-web symmetrical sections, and the design guidelines given in the current specifications, including the AISI Standard test method [6] and Eurocodes $[11,38]$, explicitly distinguish between single web sections (channel sections) and multi-web sections. Hence, the present experimental study is carried out to investigate the web crippling behaviour of roll-formed aluminium lipped channel sections.

\section{Current design rules}

The nominal web crippling capacities of cold formed lipped channel sections under the ETF and ITF load cases could be predicted using AS/NZS 1664.1 [7] and Eurocode 9 [38] for aluminium structural members, and AS/NZS 4600 [9] as well as Eurocode 3 [11] for cold-formed steel structural members.

\subsection{Aluminium structures design rules}

\subsubsection{AS/NZS 1664.1 [7]}

The web crippling design rules for flat webs subjected to a concentrated transverse load are specified in Section 4.7.7 in the AS/NZS 1664 Standard [7] Part 1 for aluminium structures. The nominal web crippling capacity $\left(P_{A S 1664}\right)$ is calculated based on Equations (1) and (2) for the ETF (where the concentrated load is applied at a distance from the member end which is less than $d / 2$ ) and ITF (where the concentrated load is applied at a distance from the member end that equals or exceeds $\mathrm{d} / 2$ ) load cases, respectively. 
$P_{A S 1664}=\frac{1.2 t^{2} \sin \theta\left(0.46 f_{y}+0.02 \sqrt{E f_{y}}\right)\left(N+C_{w 2}\right)}{C_{w 3}+r_{i}(1-\cos \theta)}$

$P_{A S 1664}=\frac{t^{2} \sin \theta\left(0.46 f_{y}+0.02 \sqrt{E f_{y}}\right)\left(N+C_{w 1}\right)}{C_{w 3}+r_{i}(1-\cos \theta)}$

where $C_{w 1}=140 \mathrm{~mm} ; \quad C_{w 2}=33 \mathrm{~mm} ; C_{w 3}=10 \mathrm{~mm} ; \mathrm{N}$ is the bearing length $(\mathrm{mm}), f_{y}$ is the static $0.2 \%$ yield stress (MPa), $E$ is the elastic modulus (MPa), $t$ is the thickness of the web (mm), $r_{i}$ is the inside corner radius ( $\mathrm{mm}$ ) and $\theta$ is the angle that is calculated from the bearing surface plane to the plane of the web surface. Note that $\theta$ is taken as $90^{\circ}$ degree for the lipped channel sections used in this experimental study.

\subsubsection{Eurocode 9 [38]}

The Eurocode 9 Standard [38] Part 1.4, Section 6.1.7.2 provides Equation (3) to estimate the web crippling strength of unstiffened webs in cold-formed aluminium members.

$P_{E C 9}=\propto t^{2} \sqrt{f_{y} E}\left(2.4+\left(\frac{\theta}{90}\right)^{2}\right)\left(1-0.1 \sqrt{\frac{r_{i}}{t}}\right)\left(0.5+\sqrt{\frac{0.02 N}{t}}\right)$

where $\propto$ is the coefficient for various local loads and support categories for cross-sections with two or more webs.

This equation is only limited to aluminium structural sheeting (members with two or more webs) and do not have the ability to estimate the web crippling capacity of single-web sections including aluminium lipped channel sections under ETF and ITF load cases. It should be noted that Eurocode 9 [38] and AS/NZS 4600 [9], as discussed in the next section, follow the same technique in predicting the web crippling capacities of cold-formed aluminium and steel sections, respectively.

\subsection{Cold formed steel design rules}

\subsubsection{AS/NZS 4600 [9]}

\subsubsection{Current design rule}

The specified web crippling strength $\left(P_{A S 4600}\right)$ according to the AS/NZS 4600 Standard [9] is calculated according to Equation (4a) for C-Sections.

$P_{A S 4600}=C t^{2} f_{y} \sin \theta\left(1-C_{R} \sqrt{\frac{r_{i}}{t}}\right)\left(1+C_{N} \sqrt{\frac{N}{t}}\right)\left(1-C_{h} \sqrt{\frac{h}{t}}\right)$

where $h$ is the flat portion of the web (mm); $C$ is the coefficient, $C_{R}$ is the coefficient of the internal corner radius, $C_{N}$ is the coefficient of the bearing length and $C_{h}$ is the coefficient of the slenderness of the web. The values of these coefficients are shown in Table 1. Note that in Equation (4a), the following conditions $h / t \leq$ 200, $N / t \leq 210, r_{i} / t \leq 3, N / h \leq 2$, and $\theta=90^{\circ}$ must be satisfied. 
After conducting an extensive parametric study on web crippling failure of cold-formed lipped channel beams (LCBs), Sundarajah et al. [25] proposed an improved unified web crippling design Equation (4b) for both ETF and ITF load cases with new coefficients as shown in Table 1. This equation has an additional factor to determine the effect of yield stress on web crippling capacity.

$P_{L A V A N}=C t^{2} \sin \theta\left(f_{y}+C_{f} \sqrt{250 f_{y}}\right)\left(1-C_{R} \sqrt{\frac{r_{i}}{t}}\right)\left(1+C_{N} \sqrt{\frac{N}{t}}\right)\left(1-C_{h} \sqrt{\frac{h}{t}}\right)$

where $C_{f}$ is the coefficient of yield stress.

\subsubsection{Eurocodes $3[11]$}

The Eurocode 3 [11] Part 1.3 for cold-formed steel structures provides several equations derived based on past experimental studies to predict the web crippling capacity for cold-formed steel sections. Equations (5) and (6) show the design formulae given in the Eurocode 3 [11] for cross sections with an unstiffened single web under ETF and ITF load cases, respectively. These equations are limited for cold-formed steel sections with $r_{i} / t \leq 6$ and $d_{w} / t \leq 200$.

$$
\begin{aligned}
& P_{E C 3}=\frac{k_{1} k_{2} k_{3} f_{y} t^{2}}{\gamma_{M 1}}\left[6.66-\frac{d_{w}}{64 t}\right]\left[1+0.01 \frac{N}{t}\right] \\
& P_{E C 3}=\frac{k_{3} k_{4} k_{5} f_{y} t^{2}}{\gamma_{M 1}}\left[21-\frac{d_{w}}{16.3 t}\right]\left[1+0.0013 \frac{N}{t}\right]
\end{aligned}
$$

where:

$$
\begin{aligned}
& k_{1}=1.33-\frac{f_{y}}{690.9} \\
& k_{2}=1.15-0.15 \frac{r_{i}}{t}\left(0.5 \leq k_{5} \leq 1.0\right) \\
& k_{3}=0.7+0.3\left(\frac{\theta}{90}\right)^{2} \\
& k_{4}=1.22-\frac{f_{y}}{1036.4} \\
& k_{5}=1.06-0.06 \frac{r_{i}}{t}\left(k_{5} \leq 1.0\right)
\end{aligned}
$$

$d_{w}$ is the web height between flange mid-lines in mm; $\gamma_{M 1}$ is the partial safety factor $\left(\gamma_{M 1}=1\right)$ and $\theta$ is taken as 90 degree.

\section{Experimental study}

\subsection{Test specimens}

Two series of web crippling tests including 40 test specimens of aluminium lipped channel sections were conducted. The sections were roll-formed from a well proven marine grade structural aluminium alloy 5052 
H36. Five different sectional sizes (with each having two nominal thicknesses ( $t$ ) of 2.5 and $3 \mathrm{~mm}$ ) which are commonly used in aluminium structural applications were tested as shown in Tables 2 and 3 . The section depth $(d)$ ranged from 100 to $250 \mathrm{~mm}$ while the nominal flange widths $\left(b_{f}\right)$ ranged from 60.5 to $75 \mathrm{~mm}$. The specimens were cut to specific length $(L)$ according to the AISI Standard test method [6]. The specimen lengths $(L)$ should be at least equal to three and five times the flat portion of the clear web height $(h)$ for the ETF and ITF load cases, respectively. All of the above mentioned dimensions were accurately measured at three points on each sample using a vernier calliper, micrometre and tap meter. The average values of these measured dimensions are presented in Tables 2 and 3 as specimen details.

Bearing plates were used as a means to apply the load or reaction forces on the specimens. They were fabricated using $450 \mathrm{MPa}$ high-strength steel. Four different bearing lengths (25, 50, 100 and $150 \mathrm{~mm}$ ) were used in both the ETF and ITF load cases in order to investigate the effect of bearing length on the web crippling capacity. During the test, the flanges of lipped channel section specimens were unfastened (not attached) to the bearing plates.

The specimens were labelled in a way that the load case, web height, thickness, as well as, the length of bearing plate could be easily identified from the label. For example, the label “ITF-10030-N50 (a)" is designated as:

- $\quad$ The first three letters indicate the load case (ETF or ITF).

- 10030 indicates the web height of $100 \mathrm{~mm}$ and the web thickness of $3.0 \mathrm{~mm}$.

- $\quad$ N50 indicates the bearing length of $50 \mathrm{~mm}$.

- If a test was repeated, then “(a)” indicates the first test and “(b)” indicates the second test.

\subsection{Material properties}

Tensile coupon tests were conducted to determine the material properties of the specimens including the yield stress, elastic modulus, ultimate strength and the stress strain-curve. Three coupons were taken from the centre, upper and bottom parts of the web plate in the longitudinal direction, similar to the roll-forming direction, for each section (10030, 15030, 20025, 20030 and 25025). The tensile coupons were prepared and tested according to the AS 1391 [39] and the American Society for Testing and Materials Standard ASTM [40] for the tensile testing of materials.

An Instron displacement controlled testing machine was used to test the coupons. The longitudinal strain was measured using a calibrated extensometer and two strain gauges (one on each side). A data acquisition system was used to record the load and strain at regular intervals during the tests. The material properties obtained from the tensile coupon tests are summarised in Table 4, which includes the average values of the elastic modulus $\left(\mathrm{E}_{0}\right), 0.2 \%$ tensile proof stress $\left(\sigma_{0.2}\right)$, ultimate tensile strength $\left(\sigma_{u}\right)$ and the strain at the fracture load $\left(\varepsilon_{\mathrm{u}}\right)$. Figure 2 shows the typical steel-strain curve of structural Aluminium alloy 5052 H36. 
Figure 2 also shows a comparison between typical stress-strain curves for aluminium alloy 5052 H36 and mild steels. It can be observed from the comparison of both stress-strain curves that they behave linear elastically with a different slope of the $\sigma-\varepsilon$ curve up to the elastic limit for the yield stress $f_{y}$ for steel and $f_{0.2}$ for aluminium. Basically, this part of the curve covers the working range of structures. After the elastic range, aluminium alloys have a continuous strain-hardening behaviour, however; mild steel is preceded by a perfectly plastic branch corresponding to yielding plateau. The ultimate deformation for aluminium alloys 5052 H36 (around 6\%) is lower than the one of mild steel (around 20\%).

\subsection{Test set-up and procedure}

Two series of forty tests were conducted using a Materials Test System (MTS) machine to investigate the web crippling capacity and behaviour of the aluminium lipped channel sections. Figures 3 (a) and (b) show the test set up for the ETF and ITF load cases, respectively. To ensure that the support at the bottom and the top are pinned, half rounds were used in the support system.

In both the ETF and ITF load cases, the specimens were positioned, respectively, at the edge and mid-span between two identical bearing plates of the same length. Then, the measured load was initialised with zero value before commencing each test. A displacement-controlled system was used to move down the cross-head of the MTS machine at a constant rate of $2 \mathrm{~mm} / \mathrm{min}$ for all test specimens until failure. The applied load as well as the vertical and horizontal displacements of the web were recorded during the tests. As shown in Figures 3 (a) and (b) three laser displacement transducers were used to measure the lateral displacement of the web in three different positions whereas one laser was used to measure the vertical displacement of the bottom flange.

\subsection{Test results and discussion}

Tables 2 and 3 present the experimental ultimate web crippling load $\left(P_{\text {Exp. }}\right)$ from the two series of tests. Two tests were repeated, and the specimens were ETF-10030-N50 and ITF-10030-N50. The differences between the repeated tests were found to be small (1.1\% for ETF-10030-N50 and 3.5\% for, ITF-10030-N50), indicating that the test results are accurate and reliable.

Figures 4 (a) and (b) show the typical load versus deflection curves from the web crippling tests for specimens

ETF-15030-N100 and ITF-15030-N150, respectively. As shown in Figure 5, web crippling is the only failure mode for the ETF specimens, however two failure modes were observed in the ITF load case. All the ITF specimens loaded by 50, 100 and 150 mm bearing lengths failed in web crippling failure mode (see Figure 6) while those with a small bearing plate $(25 \mathrm{~mm}$ ) failed in a combined flange crushing and web crippling failure as shown in Figure 7. Figure 8 (a) shows the plot of applied load versus vertical deflection for the ITF25025-N25 specimen with 25 mm bearing length. From Point-A to Point-B, the plot shows an initial increase in load with a uniform gradient and the web crippled like an arc. After Point-B, web-flange juncture started to 
deform under the bearing plates which leads to a significant reduction in the inside bent radius and therefore the section became more resistant to the bearing load and thus increased the web crippling capacity. A comparison of web crippling failure capacities as a function of bearing lengths is shown in Figure 8(b). The increased web bearing capacity of aluminium lipped channel section with small bearing plate (25 mm) was identified due to combined web crippling and flange crushing of the section. Gunalan and Mahendran [24] and Sundararajah et al. [25, 26] also observed similar kind of failures during their experimental work on coldformed steel sections.

It was also observed during the experimental study that all specimens under ITF load case and with $100 \mathrm{~mm}$ and $150 \mathrm{~mm}$ bearing plates did not reach their maximum possible web crippling capacity as their edges started to deform before reaching the ultimate load (Figures 9 (a) and (b)). In other words, the length of the influence zone extended to more than the length of the specimens. This indicates that the specimen length $(L)$ proposed by the AISI Standard test method [6] could be extended for aluminium lipped channel sections under the ITF load case. However, it should be noted that the ultimate loads obtained from this experimental study (using the test specimen lengths proposed by AISI Standard test method [6]) were conservatively compared with the current and proposed design rules.

\subsection{Comparison with current design rules}

The web crippling ultimate loads ( $P_{\text {Exp. }}$ ) obtained from the tests were compared with the nominal web crippling strengths predicted (Predicted.) using the available design rules in AS/NZS 1664.1 [7], AS/NZS 4600 [9] Sundararajah et al. [25] and Eurocode 3 [11]. Tables 5 and 6 show the comparison of the test ultimate loads $\left(P_{E x p}\right)$ with the design strengths for the ETF and ITF load cases, respectively. The design strengths were calculated using the measured cross-sectional dimensions and material properties of each specimen as detailed in Tables 2, 3 and 4.

The mean values of the test-to-predicted web crippling capacity ratio for the equations provided by AS/NZS 1664.1 [7] are 0.50 and 0.88 , whereas the corresponding coefficient of variations (COV) values are 0.37 and 0.24 for the ETF and ITF load cases, respectively (see Tables 5 and 6). This indicates that the web crippling predictions using the AS/NZS 1664.1 [7] design equations is rather unconservative with unreliable COV values for aluminium lipped channel sections under both ETF and ITF load cases.

The design strengths predicted by AS/NZS 4600 [9] are also unconservative with low mean values (0.55 for ETF and 0.78 for ITF) but with reasonably well COV value of 0.06 for the ETF load case and a high COV value of 0.17 for ITF load case. The improved equation proposed by Sundarajah et al. [25] also overly predict the web crippling capacity of aluminium lipped channel sections with mean values 0.50 and 0.59 , while the COV value is 0.08 for both ETF and ITF load cases, respectively. 
Similarly, the equations provided by Eurocode 3 [11] for cold-formed steel structures are quite unconservative with reliable COV values under the both load cases. The mean value of the test-to-predicted load ratio is 0.49 with the corresponding COV of 0.06 for the ETF load case while these values are 0.60 and 0.07 for the ITF load case.

In general, The reduced values of COV for the equations provided by Eurocode 3 [11] and Sundarajah et al. [25] mean that they could comparatively predict the effect of different height to thickness ratio $(h / t)$, bearing length to thickness ratio $(N / t)$ and radius to thickness ratio $(r / t)$ for the web crippling capacity for rolled-formed aluminium lipped channel sections under both ETF and ITF load cases. However they failed to predict the bearing capacity of aluminium lipped channel sections due to the difference in material properties as it was proposed for cold-formed steel members.

Figures 10 (a) and (b) present the test-to-predicted web crippling capacity ratios for the currently available design rules for both ETF and ITF load cases. Generally, the current design rules, as compared with the test results, failed to accurately and safely predict the web crippling capacities of aluminium lipped channel sections.

\section{Proposed design rules}

Since the current web crippling design rules based on AS/NZS 1664.1 [7], AS/NZS 4600 [9], Sundarajah et al. [25] and Eurocode 3 [11], were found to be unconservative for aluminium lipped channel sections, new design equations are proposed to predict the web crippling capacities based on the experimental results. This approach is similar to that used in the current design codes. It should be noted that the increased ultimate loads obtained from combined flange crushing and web crippling failure were not considered in this study in the development of the proposed design rules.

At present, the fabrication of roll-formed aluminium lipped channel sections in the industry is a new concept and is limited to 5052-H36 alloy. It is believed that the proposed equations based on the test results would be suitable for other aluminium alloys if their stress-strain behaviours are similar to the 5052-H36 alloy regardless of their mechanical properties values $\left(E, f_{y}\right.$ and $\left.f_{u}\right)$. The stress-strain curve behaviour of 5052-H36 aluminium alloy closely resembles the bilinear stress-stain curve (see Figure (2)) which is generally used to represent the cold-formed steel material behaviour [41]. Further FE analysis will be conducted to confirm the validity of the proposed equations for other alloys including highly rounded stress-strain curves for future applications.

\subsection{Unified design rules for aluminium and cold-formed steel lipped channel sections}

As discussed in Section 4.5, Eurocode 3 [11] and Sundarajah et al. [25] (improved AS/NZS 4600 [9] equation) are able to comparatively predict the effect of cross-section geometrical parameters $\left(h, r_{i}, t\right.$, and $\left.N\right)$ on web crippling capacity of aluminium lipped channel sections under both ETF and ITF load cases. However they failed to predict the bearing capacity of aluminium lipped channel sections due to the difference in material 
properties as they were proposed for cold-formed steel members. This section, therefore, investigates the effect of material properties (yield strength and elastic modulus) on the predicted web crippling capacity based on AS/NZS 4600 [9], Sundarajah et al. [25], Eurocode 3 [11] and the Eurocode 9 [38] design rules.

The yield strength factors $\left(k_{y}\right)$ obtained from these design rules are summarised below.

- $\mathrm{AS} / \mathrm{NZS} 4600$ [9]: $\quad k_{y}=f_{y}$

- Sundarajah et al. [25]: $\quad k_{y}=f_{y}+C_{f} \sqrt{250 f_{y}}$

- $\quad$ Eurocode 3 [11]: $\quad k_{y}=f_{y}\left(1.33-\frac{f_{y}}{690.9}\right)$

$$
k_{y}=f_{y}\left(1.22-\frac{f_{y}}{1036.4}\right)
$$

- $\quad$ Eurocode 9 [38]: $\quad k_{y}=\sqrt{f_{y}}$

Figures 11 (a) and (b) show the predicted web crippling capacity ratios (normalised based on Grade 250) with respect to yield strength for the aforementioned standards under both ETF and ITF load cases, respectively. According to the AS/NZS 4600 [9] design equations, the web crippling capacity proportionally increases with material yield strength. However, Sundarajah et al.’s [25] modification, based on extensive parametric study, has significantly reduced the effect of yield strength on the web crippling prediction compared to AS/NZS 4600 [9]. It can also be observed that the yield strength factors provided by Eurocode 3 [11], Eurocode 9 [38] and Sundarajah et al. [25] reasonably agreed well with each other as shown in Figures 11 (a) and (b).

Based on the above discussion, suitable modifications to the design rules given by AS/NZS 4600 were made. Following the same technique specified in the Eurocode 9 [38], the factor $\sqrt{E f_{y}}$ was introduced to Equation (7) to consider the effect of both yield strength (represent yield capacity) and elastic modulus (represent buckling capacity), as it plays an important role in the ultimate strength of the section. It should also be noted that this modification maintains the unit balance of the modified equation, and expand its application to the predict the web crippling capacity of both cold formed steel and rolled-formed aluminium lipped channel sections.

$P_{\text {prop. }}=C t^{2} \sqrt{E f_{y}} \sin \theta\left(1-C_{R} \sqrt{\frac{r_{i}}{t}}\right)\left(1+C_{N} \sqrt{\frac{N}{t}}\right)\left(1-C_{h} \sqrt{\frac{h}{t}}\right)$

where $C_{R}, C_{N}$ and $C_{h}$ are the coefficients proposed by Sundarajah et al. [25] (Table 1). The coefficient $C$ is empirically modified to maintain the suitability of this equation to be used for both aluminium and cold formed steel lipped channel sections ( $C=0.273$ for ETF load case, and $C=0.78$ for ITF load case).

The proposed Equation (7) can accurately predict the web crippling capacities of aluminium lipped channel sections under the ETF and ITF load cases. The mean value of the test-to-predicted load ratio is 1.00 with the corresponding COV value of 0.08, under the ETF load case, as shown in Table 5. For ITF load case, the mean value of test-to-predicted load ratio is 1.00 with the corresponding COV value of 0.05 , as shown in Table 6. 
Moreover, the web crippling test data for cold-formed lipped channels reported by Sundarajah et al. [25] was used in this study to validate the suitability of Equation (7) for cold-formed steel sections. Figures 12 (a) and (b) show a good agreement between the experimental and the predicted data for aluminium and cold-formed steel specimens.

\subsection{Australian design rules for aluminium lipped channel sections}

As Equations (1) and (2), recommended by AS/NZS 1664.1 [7], are unsafe for aluminium lipped channel sections, suitable modifications were proposed to improve their accuracy and limitation to predict the web crippling capacity for aluminium lipped channel sections under two flange load cases. Equations (8) and (9) are proposed herein incorporating modified web crippling coefficients, $C_{w 1}, C_{w 2}$ and $C_{w 3}$. It should be noted that Equations (1) and (2) do not consider the effect of web slenderness $(h / t)$ in predicting the nominal web crippling capacity. As shown in Figure 13 (a), the test-to-predicted ultimate load ratio decreases when $h / t$ increases for both the ETF and ITF load cases. Hence, the ratio $h / t$ is introduced in Equations (8) and (9) to enhance the accuracy of these equations.

$$
\begin{aligned}
& P_{A S 1664 \text { (Prop) }}=\frac{0.31 t^{2} \sin \theta\left(0.46 f_{y}+0.02 \sqrt{E f_{y}}\right)\left(N+C_{w 2}\right)}{C_{w 3}+r_{i}(1-\cos \theta)}\left(1-C_{h 1} \sqrt{\frac{h}{t}}\right) \\
& P_{A S 1664 \text { (Prop) }}=\frac{0.258 t^{2} \sin \theta\left(0.46 f_{y}+0.02 \sqrt{E f_{y}}\right)\left(N+C_{w 1}\right)}{C_{w 3}+r_{i}(1-\cos \theta)}\left(1-C_{h 2} \sqrt{\frac{h}{t}}\right)
\end{aligned}
$$

where $C_{w 1}=780 \mathrm{~mm} ; \quad C_{w 2}=238 \mathrm{~mm} ; C_{w 3}=10 \mathrm{~mm} ; C_{h 1}=0.05 \mathrm{~mm}$ and $C_{h 2}=0.025 \mathrm{~mm}$.

The proposed Equations (8) and (9) are shown to be able to accurately predict the web crippling capacities of aluminium lipped channel sections under the ETF and ITF load cases, respectively. The mean value of the test-to-predicted load ratio is 1.00 with the corresponding COV of 0.05, for the ETF load case, as shown in Table 5. The mean and COV values are 1.00 and 0.06 for the ITF load case, respectively, as shown in Table 6. Figures 13 (b) and (c) present the test to predicted ultimate load ratios obtained from the proposed equation without and with considering the effect of $h / t$ ratio, respectively.

\subsection{Eurocode design rules for aluminium lipped channel sections}

Eurocode 9 [38] and AS/NZS 4600 [9] follow the same technique in predicting the web crippling capacities of cold-formed aluminium and steel sections, respectively. Hence, the unified proposed Equation (7) can be considered as an improved equation based on Eurocode 9 [38] for aluminium single web sections. Alternatively, the design rules in the Eurocode 3 [11] is improved here and can also be employed in the Eurocode 9 for single web sections. 
Similar to the technique followed in Section 5.1, the design rules in the Eurocode 3 (Equations (5) and (6)), were modified by introducing the factor $\sqrt{E f_{y}}$ in the proposed Equations (10) and (11), with maintaining all the factors $\left(\mathrm{k}_{1}, \mathrm{k}_{2}, \mathrm{k}_{3}, \mathrm{k}_{4}, \mathrm{k}_{5}\right.$ and $\left.\mathrm{k}_{6}\right)$ as the same.

$P_{E C 3(\text { Prop. })}=\frac{0.028 k_{1} k_{2} k_{3} \sqrt{E f_{y}} t^{2}}{\gamma_{M 1}}\left[6.66-\frac{d_{w}}{64 t}\right]\left[1+0.01 \frac{N}{t}\right]$

$P_{E C 3 \text { (Prop.) }}=\frac{0.034 k_{3} k_{4} k_{5} \sqrt{E f_{y}} t^{2}}{\gamma_{M 1}}\left[21-\frac{d_{w}}{16.3 t}\right]\left[1+0.0013 \frac{N}{t}\right]$

The prediction of Equations (10) and (11) agreed well with the experimental web crippling capacities of aluminium lipped channel sections with a mean value of 1.01 and corresponding COV value of 0.06, for the ETF load case as presented in Table 5. For the ITF load case, the mean value of test-to-predicted load ratio is 0.99 with the corresponding COV value of 0.07 as shown in Table 6.

Over all, the aforementioned proposed equations (Equations (7-11)) have the ability to accurately predict the web crippling capacity of aluminium and lipped channel sections under two flange load cases as shown in Figures 12 (a) and (b).

\subsection{Capacity reduction factor $\left(\phi_{w}\right)$}

The North American Specification AISI S100 [10] recommends a statistical model to determine the capacity reduction factor. This model accounts for the variations in material, fabrication, and loading effects. The capacity reduction factor is given by Equation (12a).

$\phi_{w}=1.5 M_{m} F_{m} P_{m} e^{-\beta_{0} \sqrt{V_{M}^{2}+V_{F}^{2}+C_{n} V_{P}^{2}+V_{Q}^{2}}}$

where $\phi_{w}$ is resistance factor; $M_{m}, V_{m}=1.1,0.06$ are respectively the mean and coefficient of variation of the material factor; $F_{m}$ and $V_{F}=1.0,0.05$ are respectively the mean and coefficient of variation of the fabrication facto $r$; $V_{Q}=0.21$ is the coefficient of variation of load effect; $\beta_{0}=2.5$ is the target reliability index for

beams; $C_{n}=\frac{n^{2}-1}{n^{2}-3 n}$ is the correction factor depending on the number of tests; $P_{m}$ is the mean value of the tested to predicted load ratio: $V_{P}$ is the coefficient of variation of the test-to-predicted load ratio and $n$ is the number of tests.

Substitution of all the above values into Equation (12a) leads to the following equation.

$\phi_{w}=1.65 P_{m} e^{-2.5 \sqrt{0.0502+C_{n} V_{P}^{2}}}$ 
Equation (12b) was used to determine the capacity reduction factors for the values obtained from the design codes as well as the proposed design rules. As shown in Tables 5 and 6 , the capacity reduction factors $\left(\phi_{w}\right)$ according to the proposed equations range between 0.90 and 0.93 . Therefore, it is recommended to use a $\phi_{w}$ factor of 0.90 for all the proposed equations to predict the web crippling strengths of aluminium lipped channel sections under ETF and ITF load cases.

\section{Conclusions}

An experimental investigation of the aluminium lipped channel sections subjected to web crippling under the ETF and ITF load cases is reported herein. Forty tests were conducted with different section heights, bearing lengths and thicknesses. This paper presents a full description of the web crippling behaviour including the ultimate loads, the failure modes and the load-deformation curves. All the ETF load case specimens failed in pure web crippling while two types of failures were observed for ITF load case specimens which are the web crippling failure for specimens with 50,100 and $150 \mathrm{~mm}$ bearing plates, and the combined flange crushing and web crippling failure for specimens with $25 \mathrm{~mm}$ bearing plates. It is also found that the specimen lengths recommended by the AISI testing method [6] could be further extended for aluminium lipped channel sections under the ITF load case to achieve slightly higher capacities. The web crippling capacities of aluminium lipped channel sections obtained from the tests were then compared with the nominal strengths calculated using AS/NZS 1664.1 [7], AS/NZS 4600 [9], Sundarajah et al.’s [25] modifications, Eurocode 3 [11]. It was found that the design strengths predicted by the aforementioned specifications are quite unconservative and unsafe. Therefore, new equations were proposed based on the experimental results to accurately predict the web crippling capacities of aluminium lipped channel sections. Generally, these improved equations are capable to predict the ultimate strengths for aluminium lipped channel sections with good agreement with the experimental results.

\section{Acknowledgement}

The authors wish to thank Griffith University for providing the necessary experimental facilities and support, Robert Price from Permalite Aluminium Building Solutions Pty Ltd for supplying the test specimens, and AlHussein Bin Talal University for the financial support.

\section{References}

[1] F.M. Mazzolani, Competing issues for aluminium alloys in structural engineering, Progress in Structural Engineering and Materials, 6 (2004) 185-196.

[2] D. Kosteas, Sustainability, durability and structural advantages as leverage in promoting aluminium structures, Key Engineering Materials, 710 (2016) 13-21.

[3] C. Radlbeck, E. Dienes, D. Kosteas, Sustainability of aluminium in buildings, Structural Engineering International, 14 (2004), 221-224. 
[4] J.H. Zhu, Z.Q. Li, M.N. Su, B. Young, Behaviour of aluminium alloy plain and lipped channel columns, Thin-walled structures, 135 (2019) 306-316.

[5] G. De Matteis, G. Brando, F.M. Mazzolani, Pure aluminium: An innovative material for structural applications in seismic engineering, Construction and Building Materials, 26 (2012) 677-686.

[6] American Iron and Steel Institute, Standard test method for determining the web crippling strength of cold-formed steel beams, TS-9-05, DC, USA, 2008.

[7] Standards Australia (SA), Aluminium structures - Part 1: Limit state design, AS/NZS 1664.1, Sydney, Australia, 1997.

[8] Aluminium Association (AA), Aluminium design manual, Washington, D.C, 2015.

[9] Standards Australia (SA) (2005), Cold-formed steel structures, AS/NZS 4600, Sydney, Australia 2010.

[10] American Iron and Steel Institute, Specifications for the cold-formed steel structural members, Coldformed Steel Design Manual, AISI S100, Washington, 2012.

[11] European Committee for Standardization (CEN), Design of steel structures - Part 1.3: Cold-formed members and sheeting, EN 1993-1-3, Brussels, Belgium, 2006.

[12] R. Baehre, Sheet metal panels for use in building construction - Recent research projects in Sweden, Proceeding of the Third International Specialty Conference on Cold-formed Steel Structures, University of Missouri-Rolla, Rolla, Missouri, U.S.A., 1975.

[13] N. Hetrakul, W.W. Yu, Structural behaviour of beam webs subjected to web crippling and a combination of web crippling and bending, Final Report, Civil Engineering Study 78-4, University of Missouri-Rolla, Rolla, Missouri, U.S.A, 1978.

[14] B.A. Wing, Web Crippling and the interaction of bending and web crippling of unreinforced multiweb cold-formed steel sections, M.A.Sc. Thesis, University of Waterloo, Waterloo, ON, Canada, 1981.

[15] B.A. Wing, R.M. Schuster, Web crippling for decks subjected to two-flange loading, Proceedings of the Sixth International Specialty Conference on Cold-formed Steel Structures, University of MissouriRolla, Rolla, MO, U.S.A, 1982.

[16] C. Santaputra, Web crippling of high strength cold formed steel beams, Ph.D. Thesis, University of Missouri-Rolla, Rolla, Missouri, U.S.A, 1986.

[17] K. Prabakaran, Web crippling of cold-formed steel sections, Project Report, Department of Civil Engineering, University of Waterloo, Waterloo, Ontario, Canada, 1993.

[18] D.E. Cain, R.A. LaBoube, W.W. Yu, The effect of flange restraint on web crippling strength of cold formed steel Z-and I-sections, Final Report, Civil Engineering Study 95-2, University of MissouriRolla, Rolla, Missouri, U.S.A, 1995.

[19] R.R. Gerges, Web crippling of single web cold formed steel members subjected to end one-flange loading, M.A.Sc. Thesis, University of Waterloo, Waterloo, Ontario, Canada, (1997).

[20] R.R. Gerges, R.M. Schuster, Web crippling of single web cold formed steel members subjected to end one-flange loading, Fourth International Specialty Conference on Cold-formed Steel Structures, St. Louis, Missouri, U.S.A, 1998. 
[21] B. Beshara, R.M. Schuster, Web crippling data and calibrations of cold-formed steel members, Final Report, University of Waterloo, Waterloo, Canada, 2000.

[22] B. Young, G.J. Hancock, Design of cold-formed channels subjected to web crippling, Journal of Structural Engineering, 127 (2001) 1137-1144.

[23] M. Macdonald, M.A. Heiyantuduwa, M. Kotelko, J. Rhodes, Web crippling behaviour of thin-walled lipped channel beams, Thin-Walled Structures, 49 (2011) 682-690.

[24] S. Gunalan, M. Mahendran, Web crippling tests of cold-formed steel channels under two flange load cases, Journal of Constructional Steel Research, 110 (2015) 1-15.

[25] L. Sundararajah, M. Mahendran, P. Keerthan, New design rules for lipped channel beams subject to web crippling under two-flange load cases, Thin-Walled Structures, 119 (2017) 421-437.

[26] L. Sundararajah, M. Mahendran, P. Keerthan, Experimental studies of lipped channel beams subject to web crippling under two-flange load cases, Journal of Structural Engineering, 142 (2016) 04016058.

[27] L. Sundararajah, M. Mahendran, P. Keerthan, Web crippling studies of SupaCee sections under two flange load cases, Engineering Structures, 153 (2017) 582-597.

[28] P. Keerthan, M. Mahendran, E. Steau, Experimental study of web crippling behaviour of hollow flange channel beams under two flange load cases, Thin-Walled Structures, 85 (2014) 207-219.

[29] E. Steau, M. Mahendran, P. Keerthan, Web crippling tests of rivet fastened rectangular hollow flange channel beams under two flange load cases, Thin-Walled Structures, 95 (2015) 262-275.

[30] E. Steau, P. Keerthan, and M. Mahendran, Web crippling study of rivet fastened rectangular hollow flange channel beams with flanges fastened to supports, Advances in Structural Engineering, 20 (2017) 1059-1073.

[31] T. Tryland, M. Langseth, O.S. Hopperstad, Nonperfect aluminium beams subjected to concentrated loading, Journal of Structural Engineering, 125 (1990) 900-909.

[32] F. Zhou, B. Young, Aluminium tubular sections subjected to web crippling-Part I, Thin-Walled Structures, 46 (2008) 339-351.

[33] B. Young, F. Zhou, Aluminium tubular sections subjected to web crippling-Part II: Proposed design equations, Thin-Walled Structures, 46 (2008) 352-361.

[34] European Committee for Standardization (CEN), Design of aluminium structures - Part 1.1: General structural rules, Eurocode 9, Brussels, Belgium 2007.

[35] F. Zhou, B. Young, X.L. Zhao, Tests and design of aluminium tubular sections subjected to concentrated bearing load, Journal of Structural Engineering (C) ASCE, 135 (2009) 816-817.

[36] Y. Chen, X. Chen, C. Wang, Aluminium tubular sections subjected to web crippling, Thin-Walled Structures, 90 (2015) 49-60.

[37] M. N. Su, B. Young, Design of aluminium alloy stocky hollow sections subjected to concentrated transverse loads, Thin-Walled Structures, 124 (2018) 546-557.

[38] European Committee for Standardization (CEN), Design of aluminium structures - Part 1.4: Coldformed structural sheeting, Eurocode 9, Brussels, Belgium, 2007. 
[39] Standards Australia (SA), Methods for tensile testing of metal, AS 1391, Sydney, Australia, 2007.

[40] American Society for Testing and Materials (ASTM), Standard test methods for tension testing of metallic materials, E 8M-97, West Conshohocken, 1997.

[41] O. Zhao, S. Afshan, L. Gardner, Structural response and continuous strength method design of slender stainless steel cross-sections, Engineering Structures, 140 (2017) 14-25. 


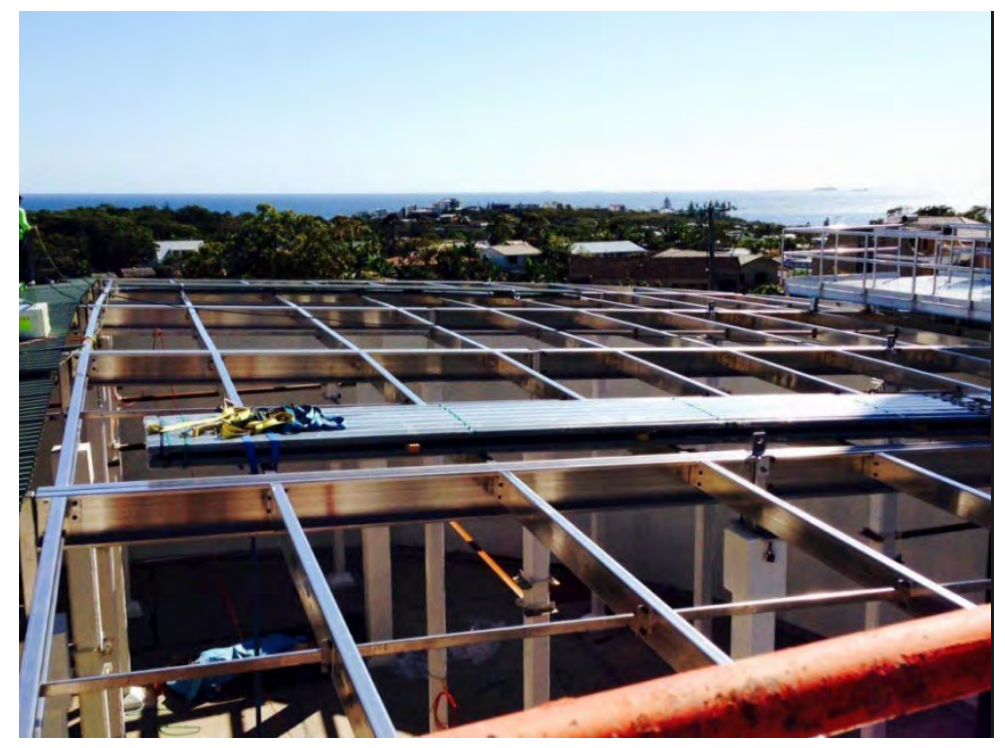

(a) Caloundra potable water reservoir, Australia

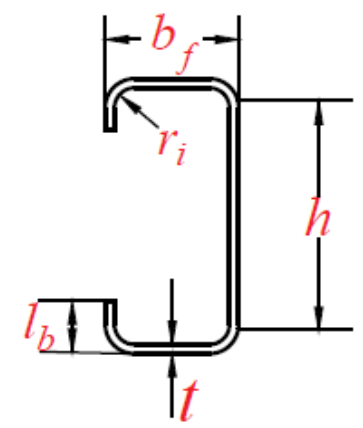

(b) Typical lipped channel cross section

Figure 1: Roll-formed aluminium members.

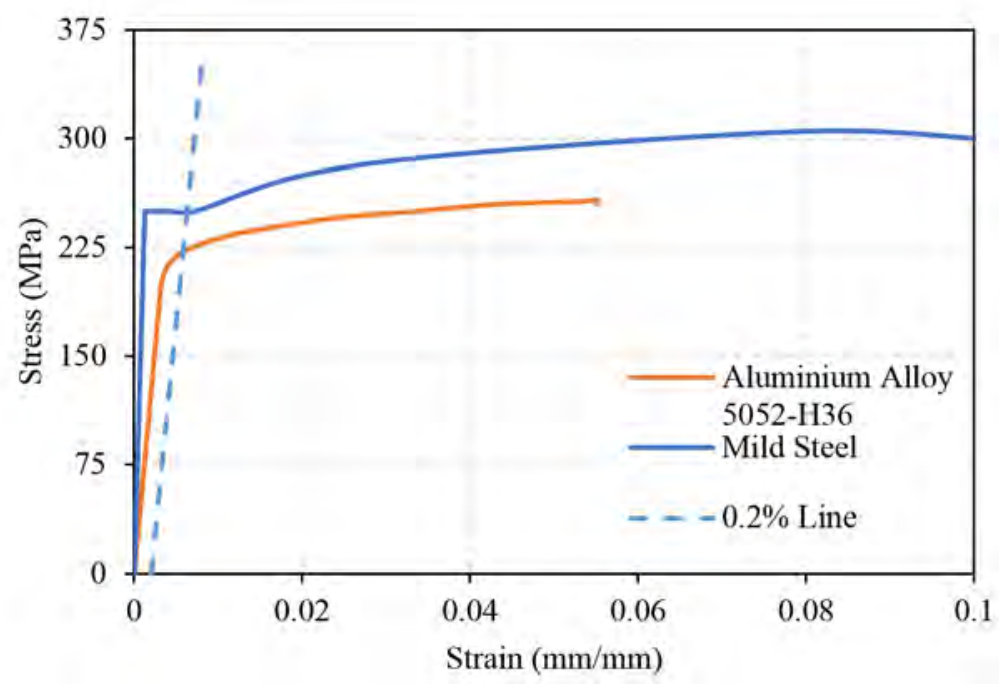

Figure 2: Measured tensile stress-strain plot of structural aluminium alloy 5052 H36. 


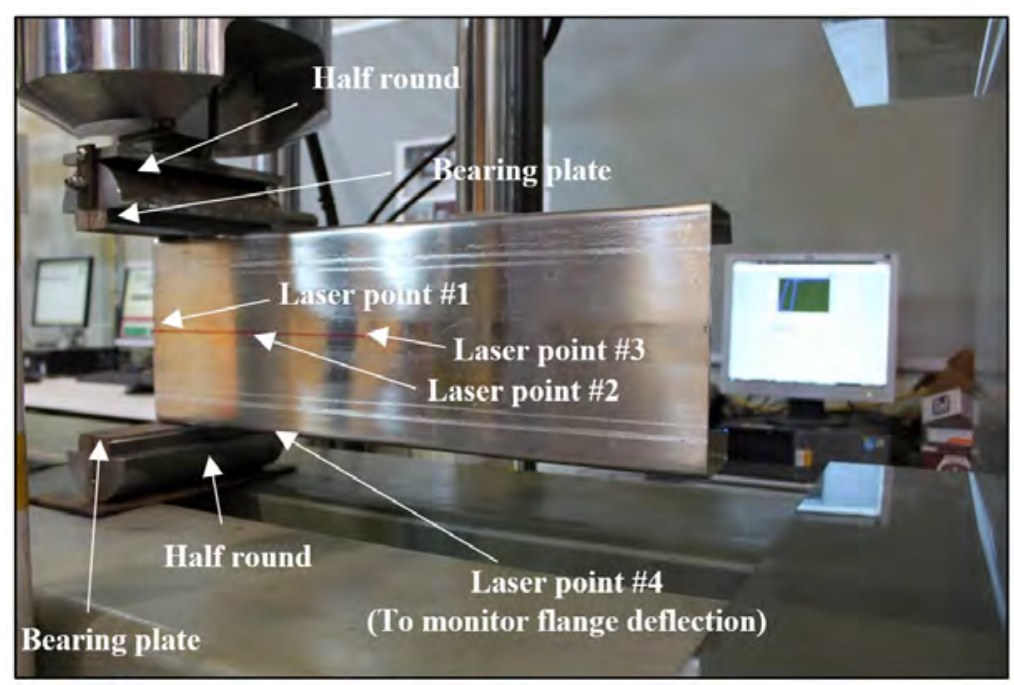

(a) ETF load case.

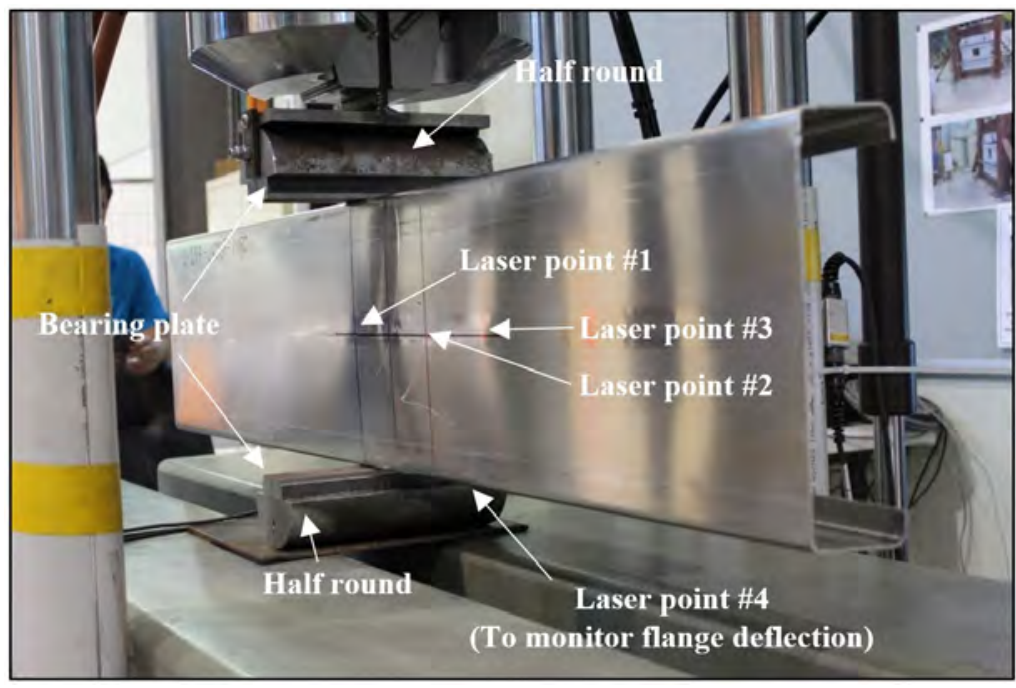

(b) ITF load case

Figure 3: Web crippling test setups. 


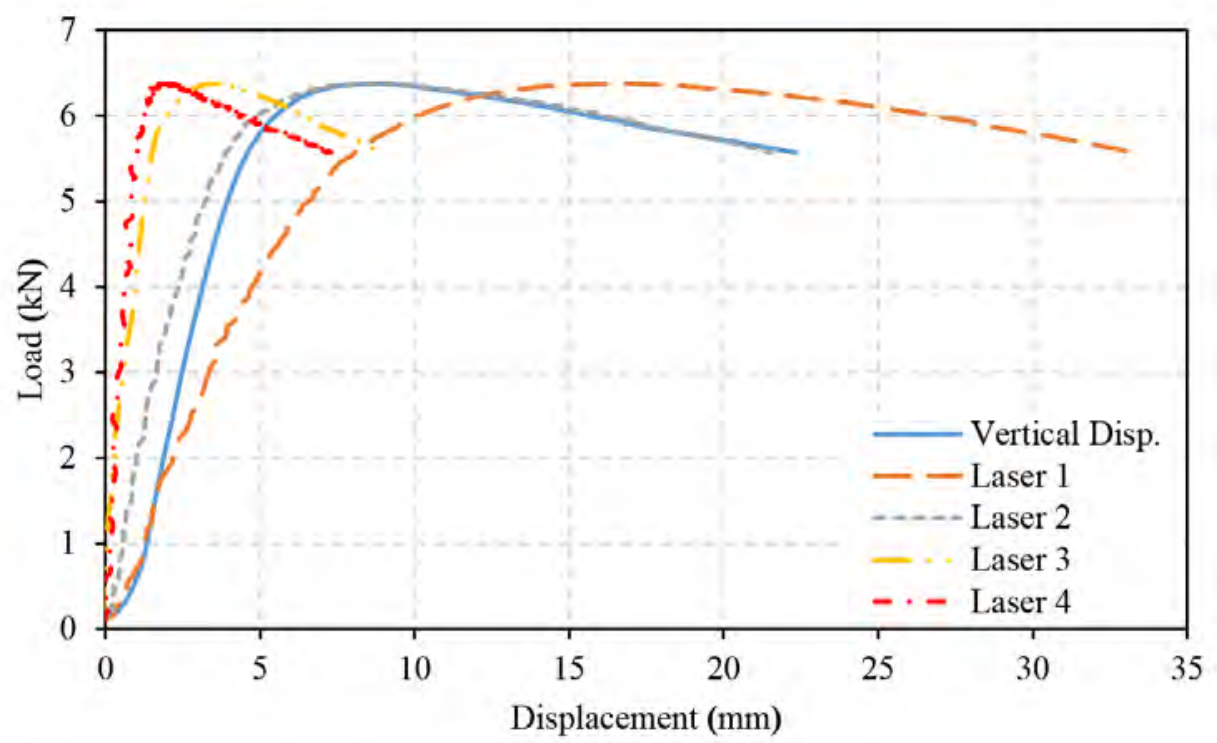

(a) ETF-15030-N100

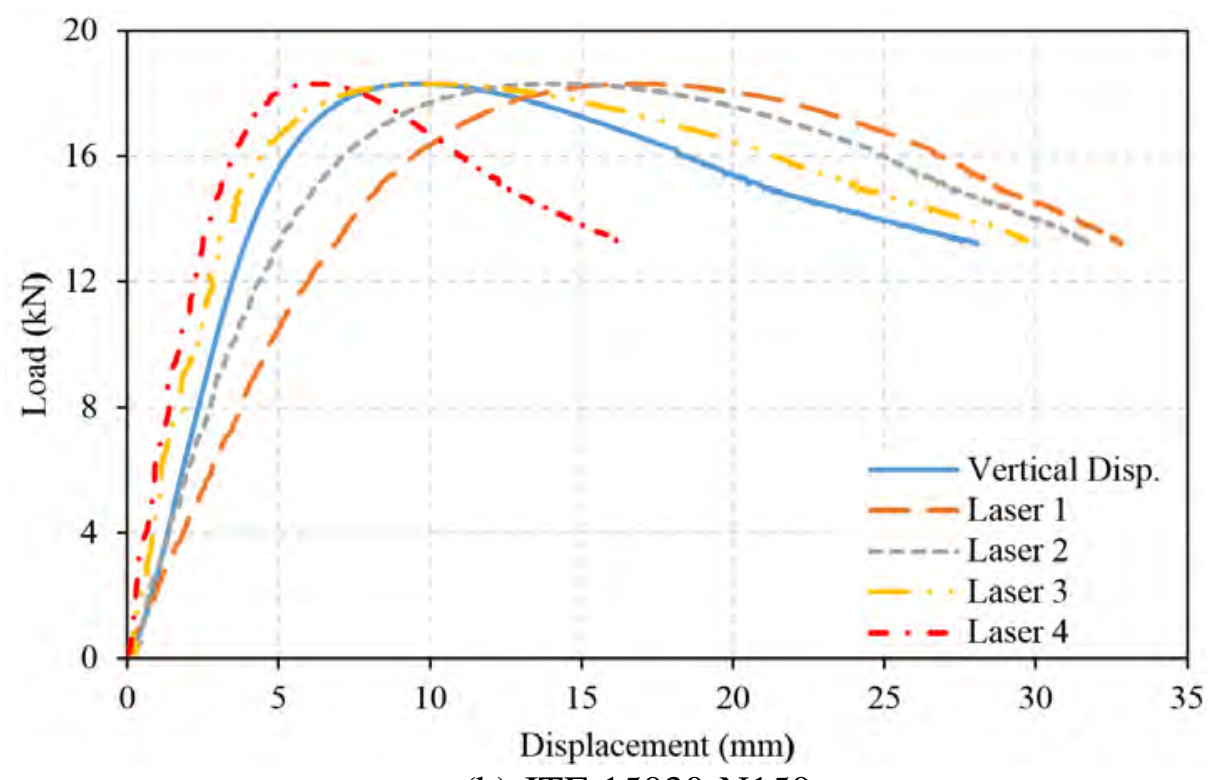

(b) ITF-15030-N150

Figure 4: Typical load versus deflection curves.

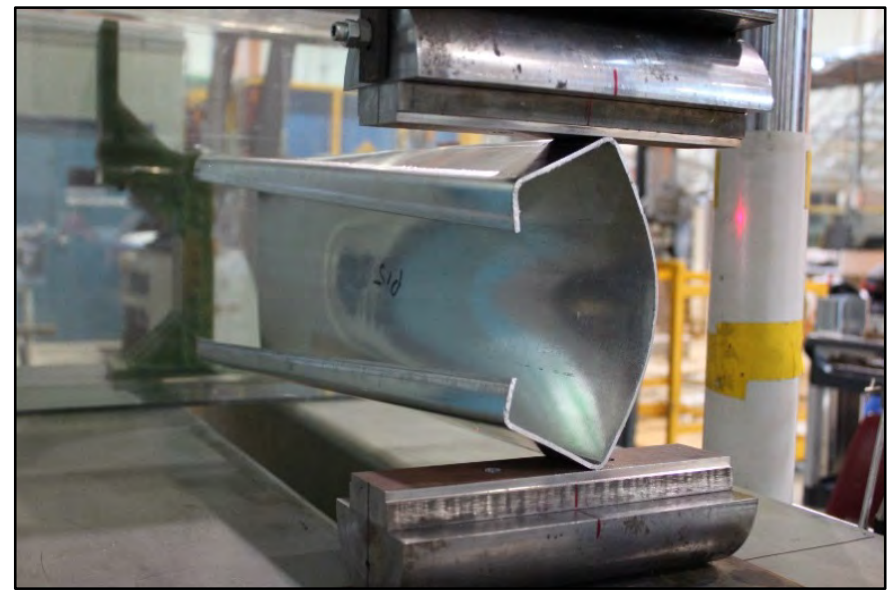

(a) ETF-20025-N50

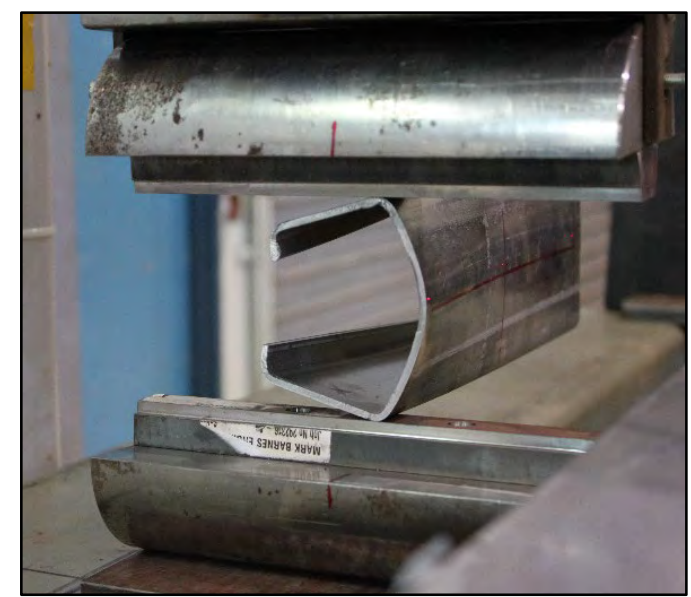

(b) ETF-10025-N25 


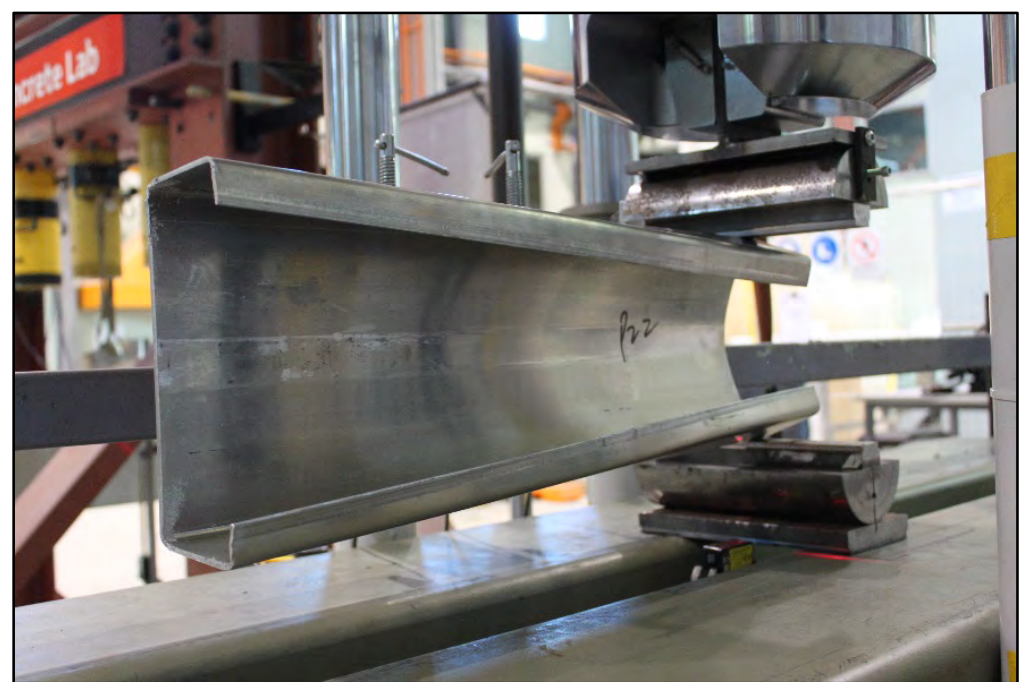

(c) ETF-20025-N25

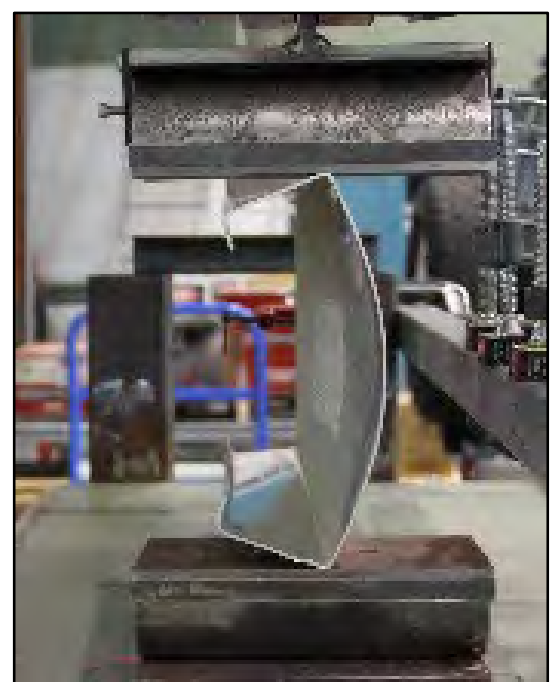

(d) ETF-25025-N150

Figure 5: Web crippling failure modes for ETF load case.

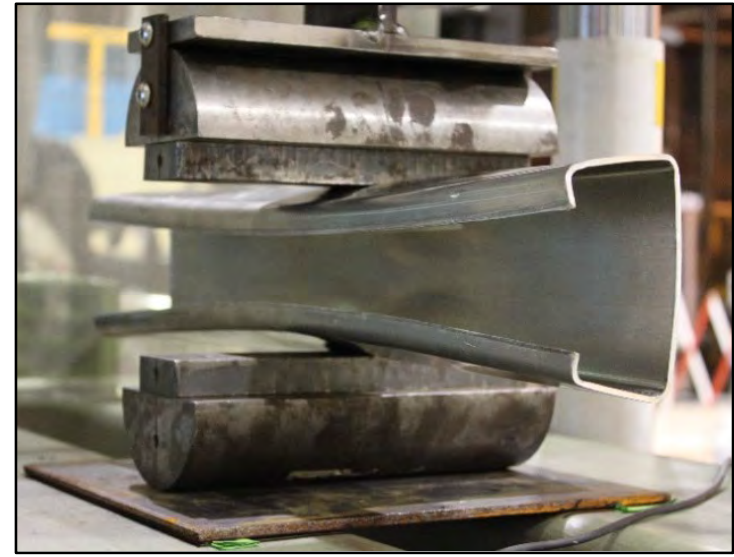

(a) ITF-10030-N50

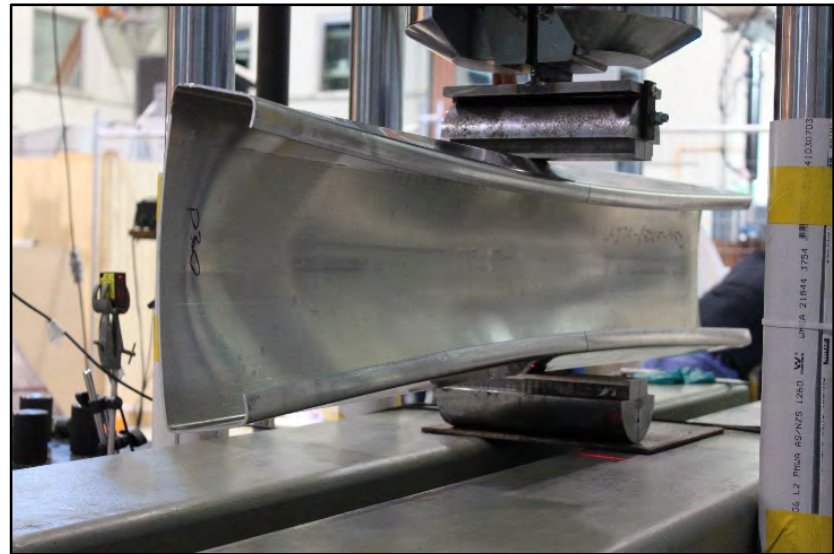

(b) ITF-25025-N50

Figure 6: Web crippling failure modes for ITF load case. 


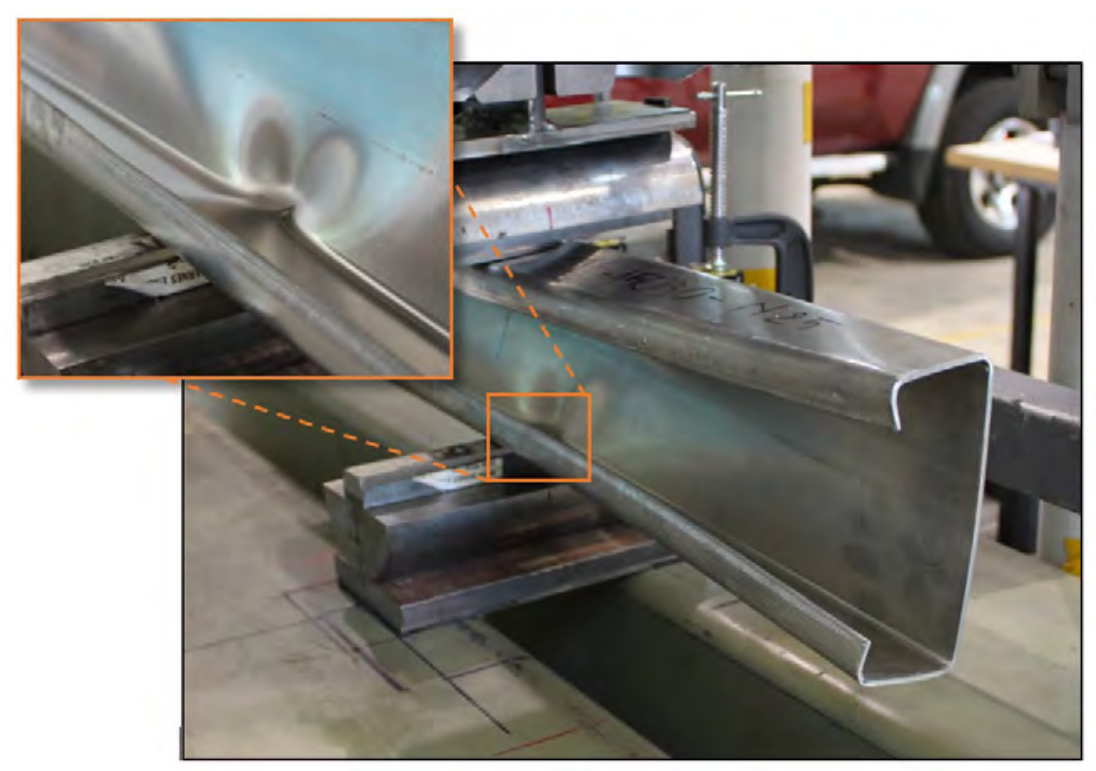

Figure 7: Combined flange crushing and web crippling failure for ITF-15030-N25.

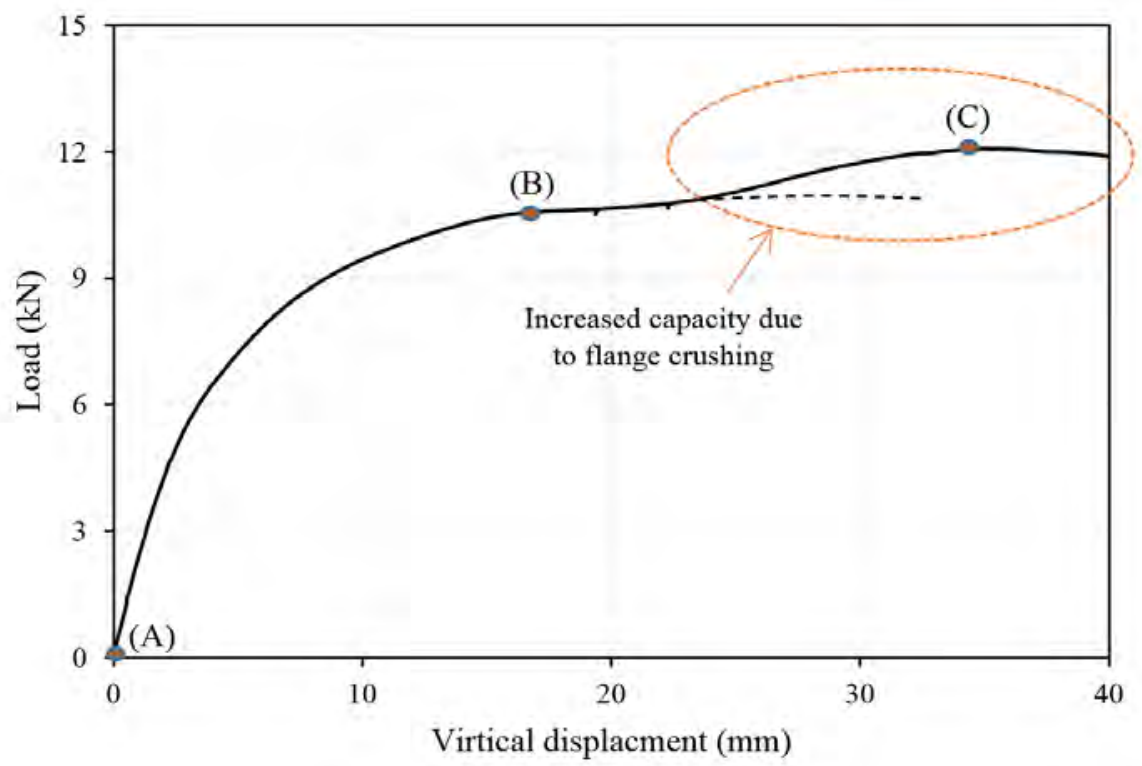

(a) Applied load versus vertical deflection 


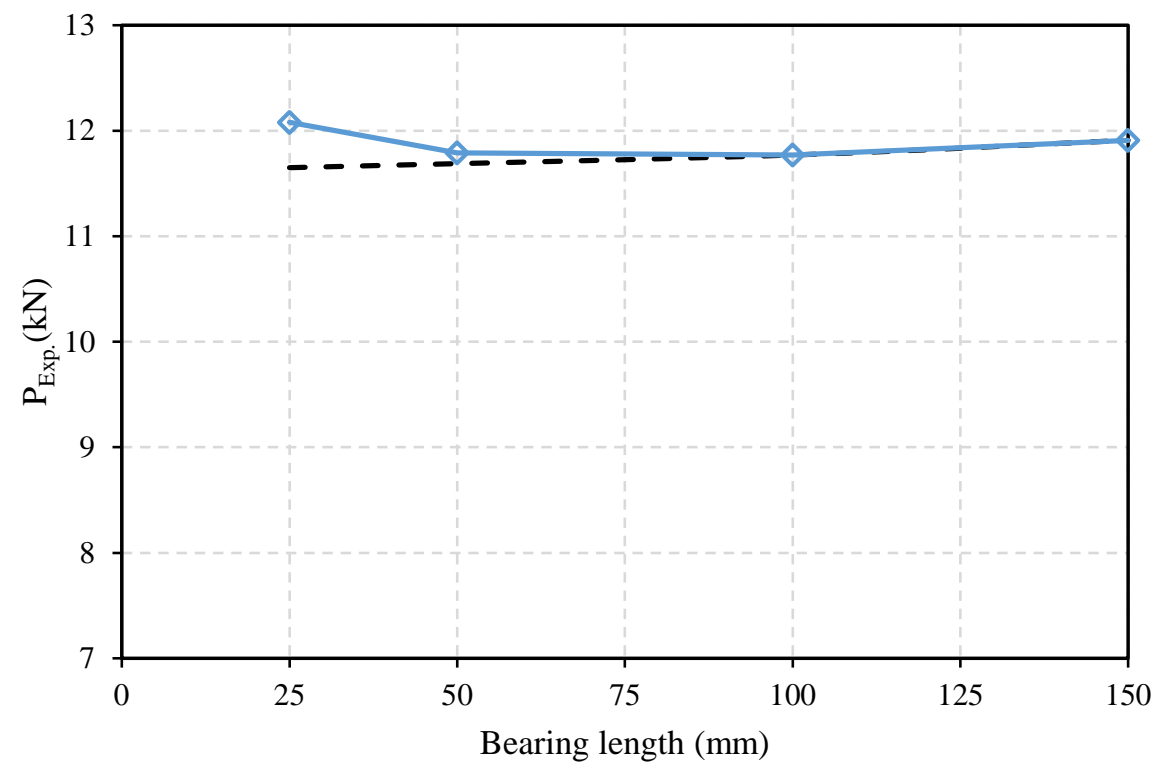

(b) Failure load versus bearing length

Figure 8: Flange crushing failure mechanism of ITF-25025-N25.

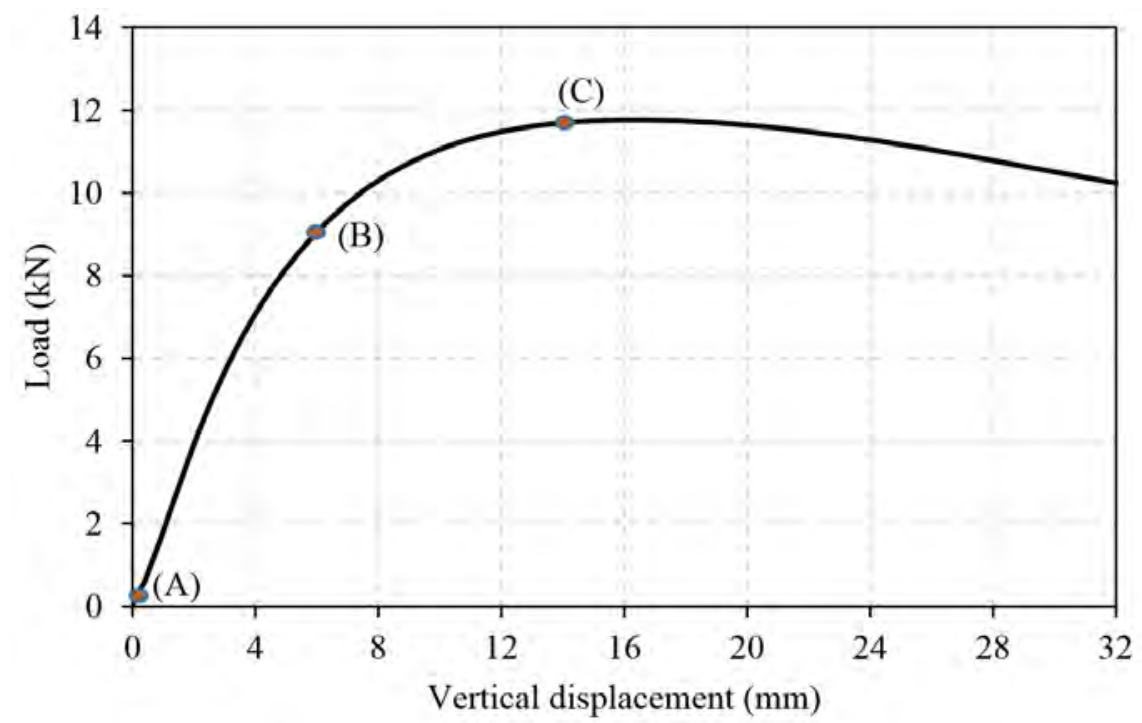

(a) Applied load versus vertical deflection curve

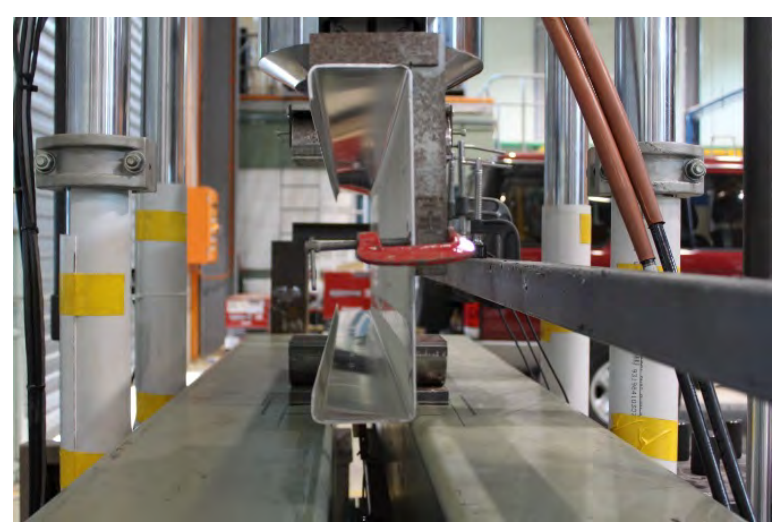

Stage - A (Initial)

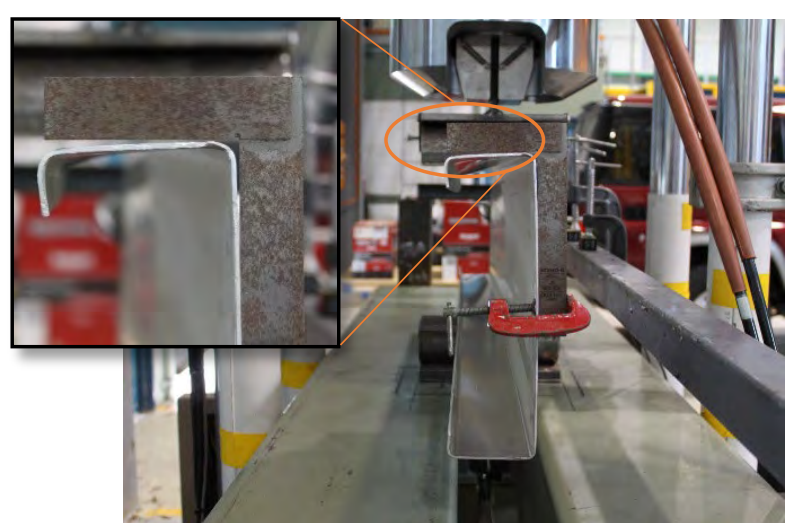

Stage - B (Section ends started to deform) 


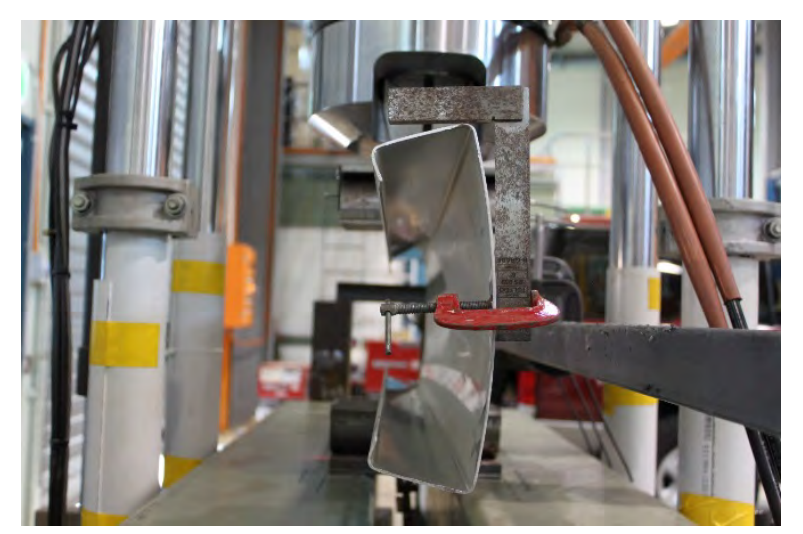

Stage - C (Failure)

(b) Failure modes in different stages during the test

Figure 9: Test results for ITF-25025-N100.

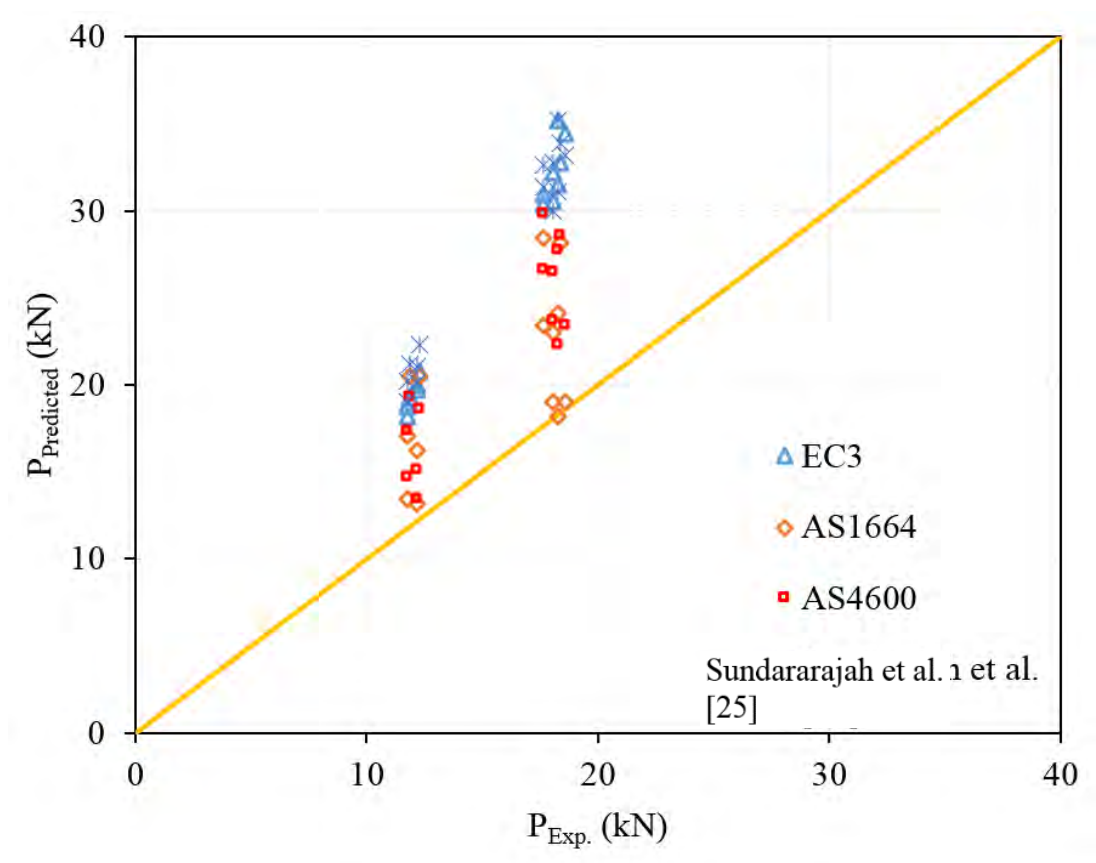

(a) ETF load case

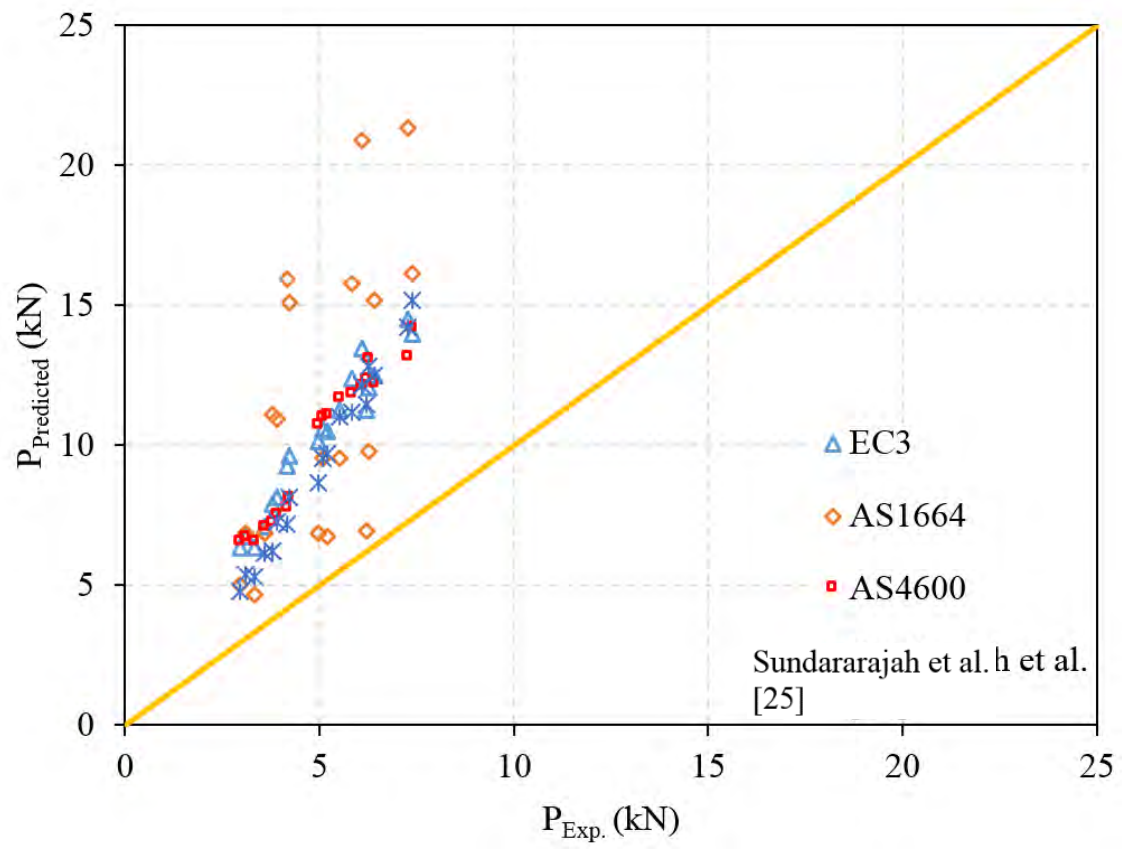

(b) ITF load case

Figure 10: Web crippling capacities from tests and current design rules. 


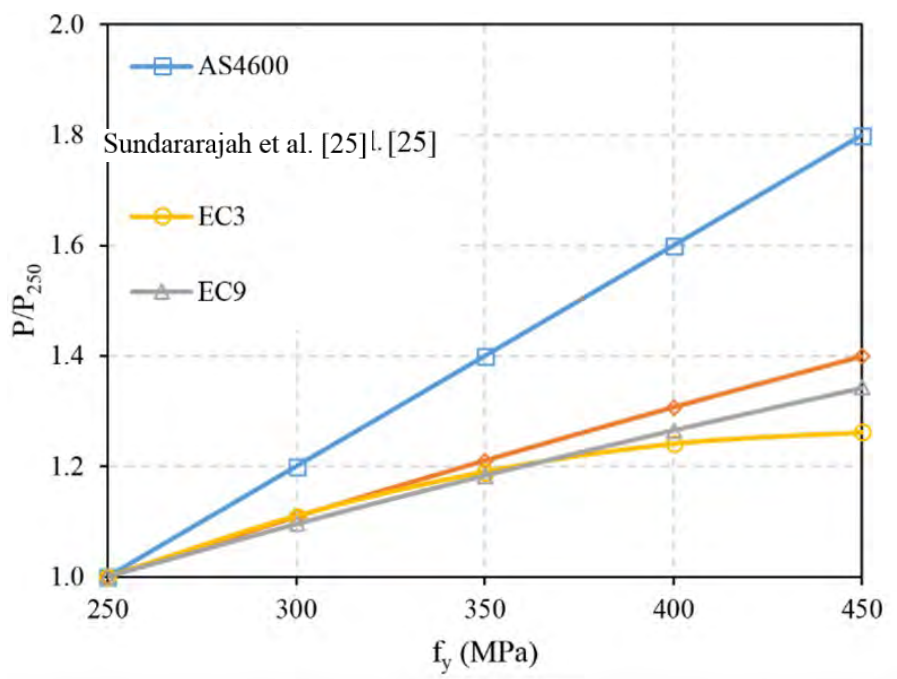

(a) ETF load case

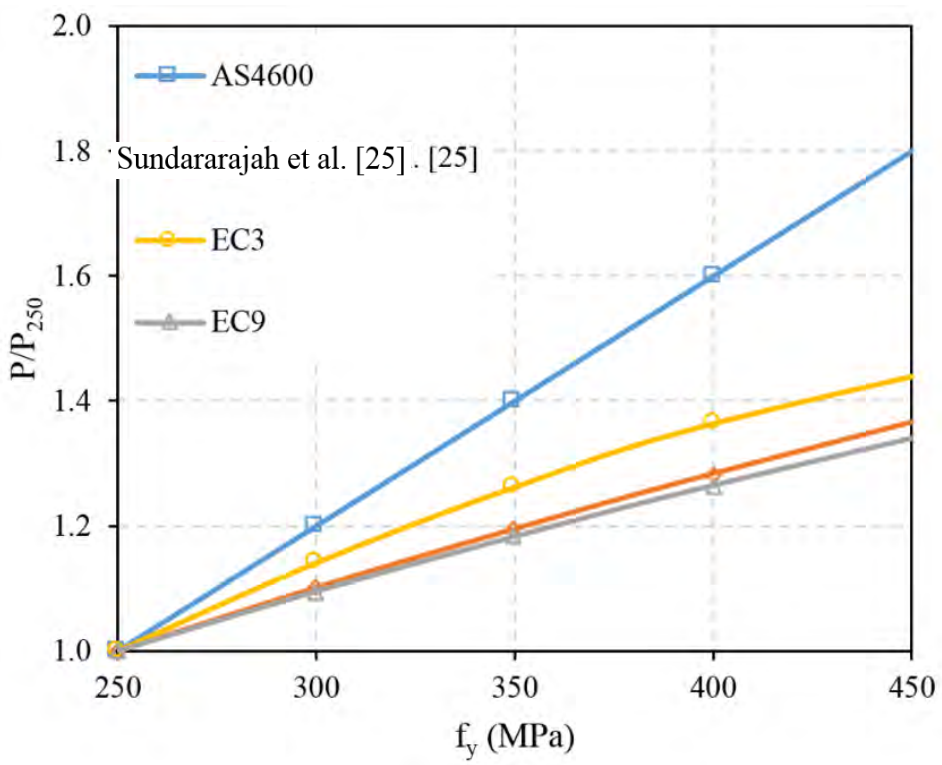

(b) ITF load case

Figure 11: Effect of material yield strength on web crippling capacity. 


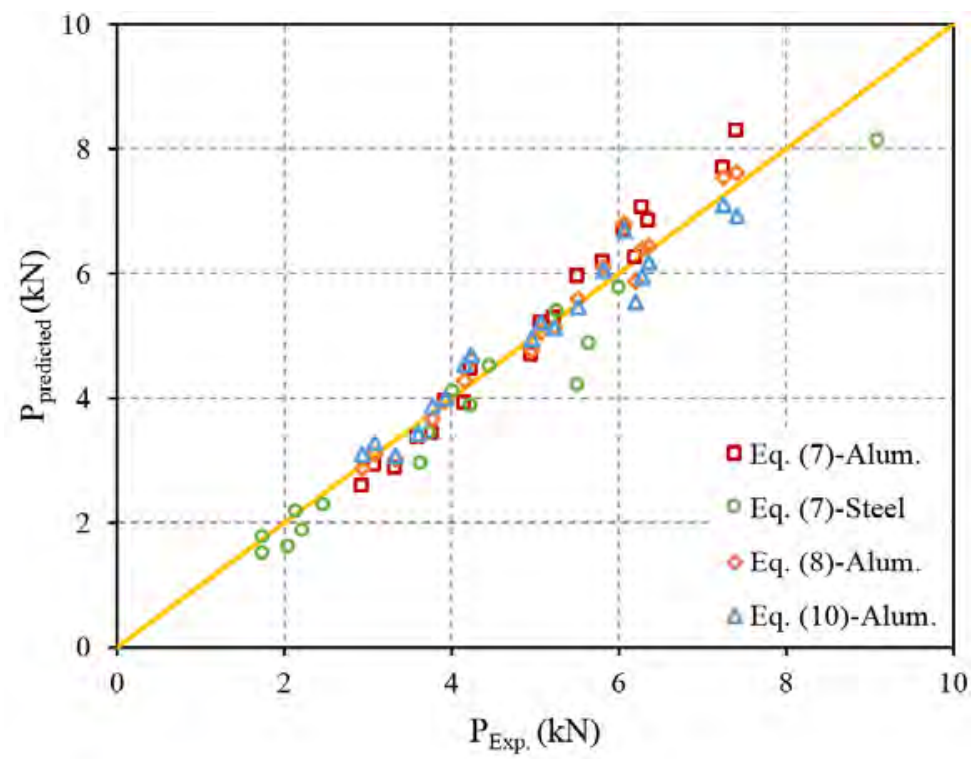

(a) ETF load case

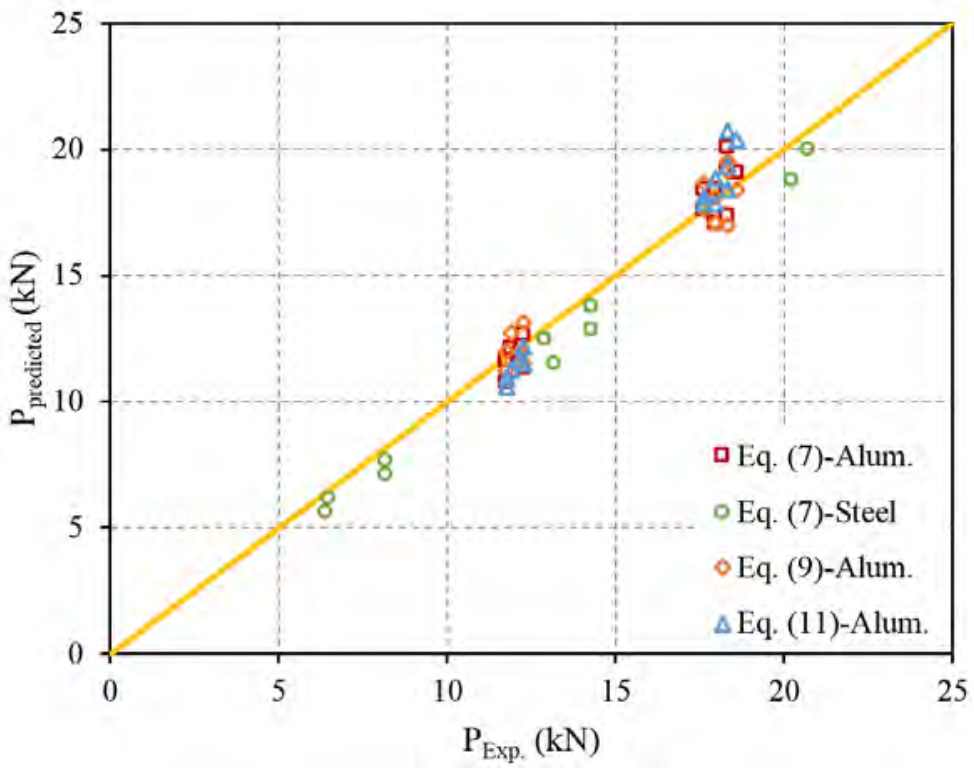

(b) ITF load case

Figure 12: Web crippling capacities from tests (current study and Sundarajah [25]) and proposed design rules. 


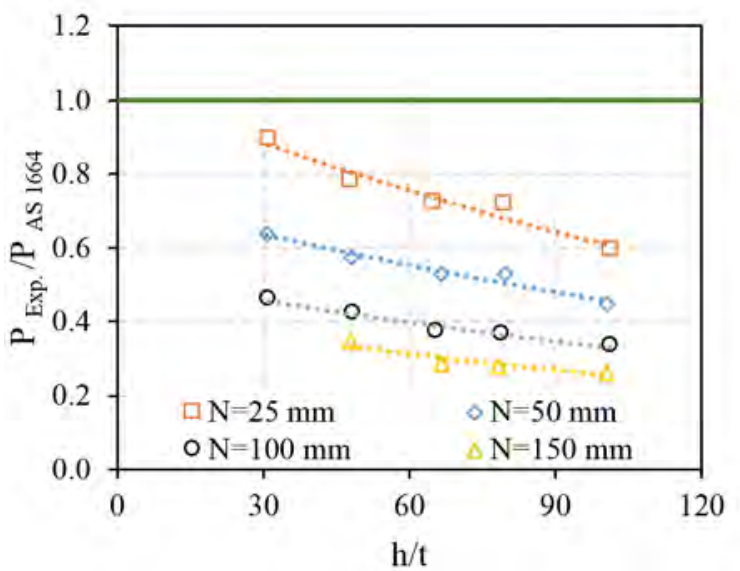

(ETF)

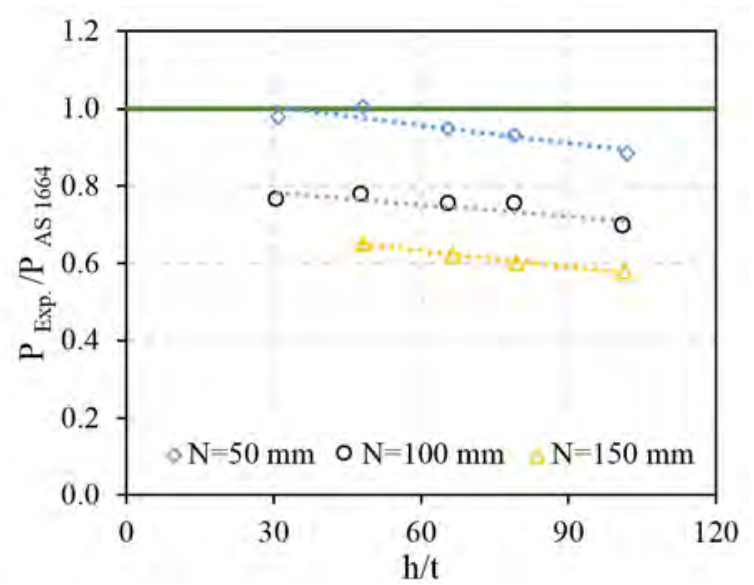

(ITF)

(a) Current design rule

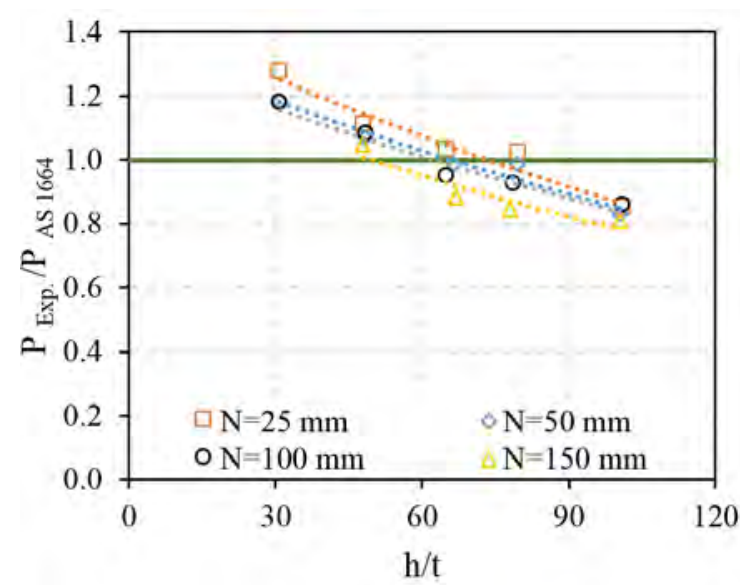

(ETF)

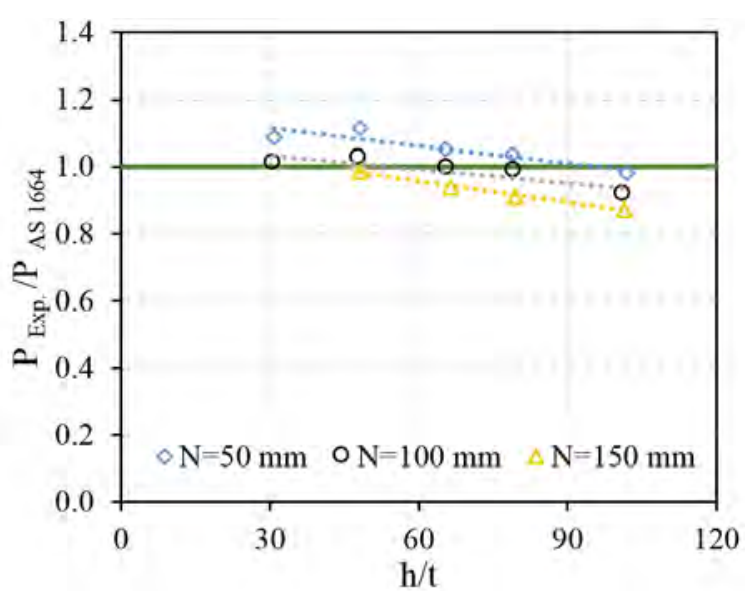

(ITF)

(b) Proposed design rule - without considering the effect of $h / t$

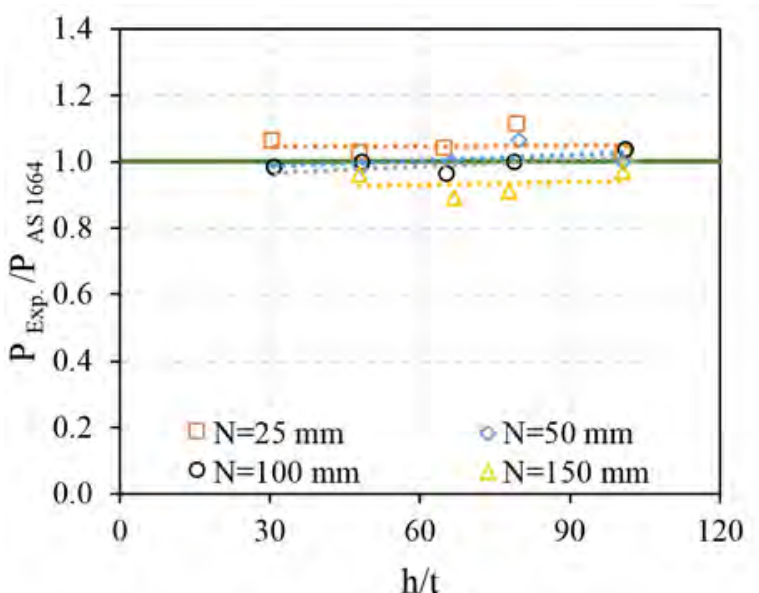

(ETF)

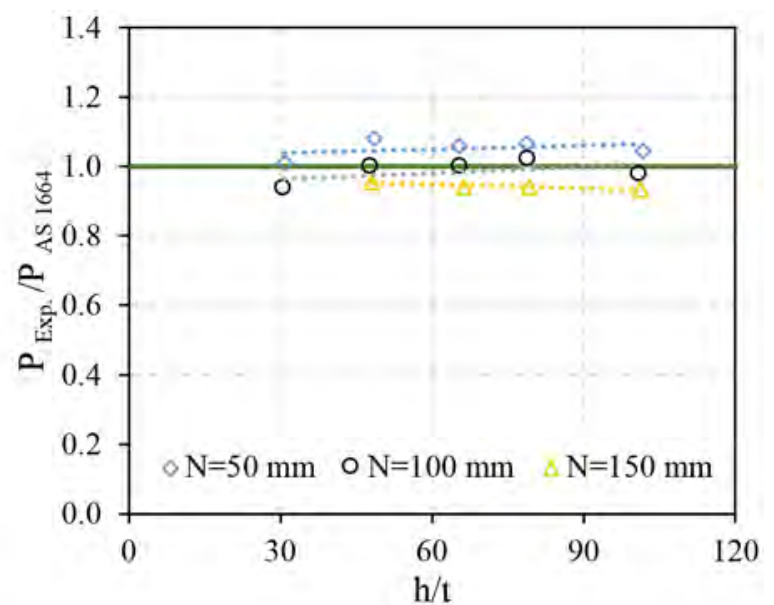

(ITF)

(c) Proposed design rule - with considering the effect of $h / t$

Figure 13: Comparison of test-to-predicted capacity ratios for current and proposed design rules. 
Table 1: AS/NZS 4600 [9] and Sundarajah et al. [225] coefficients for lipped channel sections.

\begin{tabular}{cccccccc}
\hline Equation & $\begin{array}{c}\text { Load } \\
\text { case }\end{array}$ & $C$ & $C_{R}$ & $C_{N}$ & $C_{h}$ & $C_{f}$ & LRFD $\phi_{w}$ \\
\hline AS/NZS 4600 [9] & ETF & 13 & 0.32 & 0.05 & 0.04 & - & 0.90 \\
& ITF & 24 & 0.52 & 0.15 & 0.001 & - & 0.80 \\
Sundarajah et al. [25] & ETF & 1.03 & 0.21 & 0.16 & 0.06 & 6.85 & 0.85 \\
& ITF & 1.24 & 0.17 & 0.04 & 0.03 & 16.90 & 0.88 \\
\hline
\end{tabular}

Table 2: Test specimen details and results for ETF load case.

\begin{tabular}{lccccccc}
\hline \multicolumn{1}{c}{ Specimen } & $\begin{array}{c}\text { Depth } \\
\text { Flange }\end{array}$ & $\begin{array}{c}\text { Lip } \\
b_{f}(\mathrm{~mm})\end{array}$ & $\begin{array}{c}\text { Thickness } \\
{ }_{b}(\mathrm{~mm})\end{array}$ & $\begin{array}{c}\text { Radius } \\
(\mathrm{mm})\end{array}$ & $\begin{array}{c}\text { Length } \\
r_{i}(\mathrm{~mm})\end{array}$ & $\begin{array}{c}\text { Load } \\
(\mathrm{mm})\end{array}$ & $P_{\text {Exp. }}(\mathrm{kN})$ \\
\hline ETF-10030-N25 & 107.3 & 60.4 & 14.9 & 2.95 & 4.9 & 316 & 6.19 \\
ETF-10030-N50(a) & 106.5 & 58.4 & 16.1 & 2.95 & 5.0 & 317 & 6.23 \\
ETF-10030-N50(b) & 107.1 & 59.7 & 15.1 & 2.97 & 4.9 & 317 & 6.30 \\
ETF-10030-N100 & 107.3 & 59.4 & 15.0 & 2.95 & 4.8 & 316 & 7.41 \\
ETF-15030-N25 & 156.7 & 62.8 & 22.9 & 2.93 & 4.9 & 466 & 5.23 \\
ETF-15030-N50 & 157.5 & 63.3 & 22.4 & 2.93 & 5.0 & 465 & 5.50 \\
ETF-15030-N100 & 158.3 & 63.5 & 21.7 & 2.92 & 5.1 & 465 & 6.37 \\
ETF-15030-N150 & 155.5 & 63.5 & 22.9 & 2.92 & 4.9 & 467 & 7.25 \\
ETF-20025-N25 & 208.1 & 74.6 & 25.5 & 2.42 & 5.1 & 617 & 3.33 \\
ETF-20025-N50 & 208.1 & 74.2 & 25.4 & 2.43 & 4.9 & 615 & 3.61 \\
ETF-20025-N100 & 207.3 & 74.3 & 25.7 & 2.43 & 5.0 & 615 & 3.92 \\
ETF-20025-N150 & 204.0 & 75.8 & 26.5 & 2.43 & 4.8 & 615 & 4.23 \\
ETF-20030-N25 & 204.6 & 74.9 & 27.4 & 2.9 & 4.6 & 611 & 4.95 \\
ETF-20030-N50 & 208.4 & 73.0 & 27.5 & 2.9 & 5.0 & 615 & 5.07 \\
ETF-20030-N100 & 204.5 & 75.4 & 27.7 & 2.89 & 4.6 & 613 & 5.82 \\
ETF-20030-N150 & 208.3 & 73.5 & 27.1 & 2.89 & 5.0 & 615 & 6.06 \\
ETF-25025-N25 & 259.8 & 80.8 & 23.4 & 2.43 & 4.4 & 765 & 2.95 \\
ETF-25025-N50 & 259.9 & 76.1 & 23.7 & 2.44 & 4.9 & 765 & 3.09 \\
ETF-25025-N100 & 262.1 & 76.2 & 22.7 & 2.44 & 4.8 & 765 & 3.76 \\
ETF-25025-N150 & 260.3 & 76.3 & 23.4 & 2.45 & 4.6 & 765 & 4.15 \\
\hline
\end{tabular}

Note: ETF-10030-N50(a) and ETF-10030-N50(b) were repeated tests 
Table 3: Test specimen details and results for ITF load case.

\begin{tabular}{|c|c|c|c|c|c|c|c|}
\hline Specimen & $\begin{array}{l}\text { Depth } \\
d(\mathrm{~mm})\end{array}$ & $\begin{array}{c}\text { Flange } \\
b_{f}(\mathrm{~mm})\end{array}$ & $\begin{array}{c}\text { Lip } \\
l_{b}(\mathrm{~mm})\end{array}$ & $\begin{array}{c}\text { Thickness } \\
t(\mathrm{~mm})\end{array}$ & $\begin{array}{l}\text { Radius } \\
r_{i}(\mathrm{~mm})\end{array}$ & $\begin{array}{l}\text { Length } \\
L(\mathrm{~mm})\end{array}$ & $\begin{array}{c}\text { Load } \\
P_{\text {Exp. }}(\mathrm{kN})\end{array}$ \\
\hline ITF-10030-N25 & 106.9 & 59.3 & 14.3 & 2.94 & 4.8 & 527 & 21.40 \\
\hline ITF-10030-N50(a) & 106.4 & 59.4 & 14.8 & 2.95 & 4.9 & 525 & 18.90 \\
\hline ITF-10030-N50(b) & 106.9 & 59.0 & 14.4 & 2.94 & 4.9 & 521 & 18.23 \\
\hline ITF-10030-N100 & 106.1 & 59.6 & 14.4 & 2.94 & 4.8 & 523.5 & 18.29 \\
\hline ITF-15030-N25 & 156.5 & 62.6 & 22.6 & 2.93 & 4.8 & 774 & 18.71 \\
\hline ITF-15030-N50 & 156.7 & 62.4 & 22.7 & 2.92 & 4.9 & 775 & 18.29 \\
\hline ITF-15030-N100 & 156.2 & 62.1 & 22.7 & 2.92 & 4.8 & 776 & 18.00 \\
\hline ITF-15030-N150 & 156.6 & 62.5 & 22.8 & 2.93 & 4.9 & 774 & 18.30 \\
\hline ITF-20025-N25 & 206.2 & 74.0 & 26.3 & 2.43 & 4.6 & 1028 & 12.82 \\
\hline ITF-20025-N50 & 207.2 & 73.3 & 26.0 & 2.44 & 4.9 & 1022 & 12.23 \\
\hline ITF-20025-N100 & 207.3 & 73.9 & 26.3 & 2.43 & 5.0 & 1019 & 12.19 \\
\hline ITF-20025-N150 & 207.4 & 73.4 & 26.9 & 2.44 & 4.6 & 1021 & 12.27 \\
\hline ITF-20030-N25 & 205.6 & 74.5 & 31.6 & 2.9 & 4.4 & 1022 & 18.12 \\
\hline ITF-20030-N50 & 206.6 & 75.3 & 27.4 & 2.93 & 4.8 & 102 & 18.00 \\
\hline ITF-20030-N100 & 206.5 & 74.4 & 26.7 & 2.9 & 4.8 & 1021 & 17.59 \\
\hline ITF-20030-N150 & 206.5 & 74.5 & 26.7 & 2.89 & 4.6 & 1022 & 17.62 \\
\hline ITF-25025-N25 & 259.9 & 76.1 & 22.1 & 2.43 & 4.4 & 1273 & 12.08 \\
\hline ITF-25025-N50 & 260.0 & 76.0 & 22.4 & 2.42 & 4.5 & 1274 & 11.79 \\
\hline ITF-25025-N100 & 259.8 & 76.3 & 22.5 & 2.43 & 4.5 & 1269 & 11.77 \\
\hline ITF-25025-N150 & 259.9 & 76.2 & 22.2 & 2.43 & 4.5 & 1275 & 11.91 \\
\hline
\end{tabular}

Note: ITF-10030-N50(a) and ITF-10030-N50(b) were repeated tests

Table 4: Mechanical properties of aluminium sections used in the experimental study.

\begin{tabular}{ccccc}
\hline Section & $\begin{array}{c}E_{0} \\
(\mathrm{GPa})\end{array}$ & $\begin{array}{c}\sigma_{0.2} \\
(\mathrm{MPa})\end{array}$ & $\begin{array}{c}\sigma_{u} \\
(\mathrm{MPa})\end{array}$ & $\begin{array}{c}\varepsilon_{u} \\
(\%)\end{array}$ \\
\hline 10030 & 65.05 & 210 & 259 & 6.15 \\
15030 & 63.55 & 206 & 248 & 5.55 \\
20025 & 63.95 & 214 & 260 & 5.05 \\
20030 & 64.13 & 212 & 257 & 6.47 \\
25025 & 64.34 & 216 & 265 & 6.68 \\
\hline
\end{tabular}


Table 5: Experimental ultimate loads and comparisons with current and proposed design rules - ETF load case.

\begin{tabular}{|c|c|c|c|c|c|c|c|c|c|}
\hline \multirow[b]{2}{*}{ Specimen } & \multirow[b]{2}{*}{$h / t$} & \multirow[b]{2}{*}{$\begin{array}{l}P_{\text {Exp. }} . \\
(\mathrm{kN})\end{array}$} & \multirow[b]{2}{*}{$P_{\text {AS1664 }}$} & \multirow[b]{2}{*}{$P_{\text {AS4600 }}$} & \multicolumn{5}{|c|}{ Ultimate load ratios (Test/Prediction) } \\
\hline & & & & & $P_{\text {Sundararajah }}$ & $P_{\text {EC3 }}$ & $\begin{array}{c}P \\
\text { (Prop.) }\end{array}$ & $\begin{array}{l}P_{\text {AS1664 }} \\
\text { (Prop.) }\end{array}$ & $\begin{array}{c}\text { PeC3 } \\
\text { (Prop.) }\end{array}$ \\
\hline ETF-10030-N25 & 31.1 & 6.19 & 0.89 & 0.50 & 0.54 & 0.55 & 0.99 & 1.06 & 1.12 \\
\hline ETF-10030-N50 & 30.7 & 6.27 & 0.64 & 0.48 & 0.49 & 0.52 & 0.89 & 0.98 & 1.06 \\
\hline ETF-10030-N100 & 31.1 & 7.41 & 0.46 & 0.52 & 0.49 & 0.53 & 0.90 & 0.97 & 1.08 \\
\hline ETF-15030-N25 & 48.1 & 5.23 & 0.78 & 0.47 & 0.54 & 0.50 & 0.99 & 1.02 & 1.02 \\
\hline ETF-15030-N50 & 48.4 & 5.50 & 0.58 & 0.47 & 0.50 & 0.49 & 0.92 & 0.99 & 1.00 \\
\hline ETF-15030-N100 & 48.7 & 6.37 & 0.42 & 0.52 & 0.51 & 0.51 & 0.93 & 0.99 & 1.03 \\
\hline ETF-15030-N150 & 47.9 & 7.25 & 0.34 & 0.55 & 0.51 & 0.50 & 0.94 & 0.96 & 1.02 \\
\hline ETF-20025-N25 & 79.8 & 3.33 & 0.72 & 0.51 & 0.63 & 0.53 & 1.15 & 1.11 & 1.10 \\
\hline ETF-20025-N50 & 79.6 & 3.61 & 0.53 & 0.51 & 0.59 & 0.51 & 1.07 & 1.07 & 1.06 \\
\hline ETF-20025-N100 & 79.2 & 3.92 & 0.36 & 0.52 & 0.54 & 0.48 & 1.00 & 0.99 & 0.99 \\
\hline ETF-20025-N150 & 78.0 & 4.23 & 0.28 & 0.52 & 0.52 & 0.44 & 0.95 & 0.91 & 0.91 \\
\hline ETF-20030-N25 & 65.3 & 4.95 & 0.72 & 0.46 & 0.57 & 0.49 & 1.05 & 1.04 & 1.01 \\
\hline ETF-20030-N50 & 66.4 & 5.07 & 0.53 & 0.46 & 0.53 & 0.48 & 0.97 & 1.00 & 0.98 \\
\hline ETF-20030-N100 & 65.6 & 5.82 & 0.37 & 0.49 & 0.52 & 0.47 & 0.94 & 0.95 & 0.97 \\
\hline ETF-20030-N150 & 66.6 & 6.06 & 0.29 & 0.50 & 0.50 & 0.45 & 0.91 & 0.89 & 0.92 \\
\hline ETF-25025-N25 & 101.3 & 2.95 & 0.59 & 0.45 & 0.62 & 0.47 & 1.14 & 1.02 & 0.97 \\
\hline ETF-25025-N50 & 100.5 & 3.09 & 0.45 & 0.46 & 0.58 & 0.46 & 1.06 & 1.00 & 0.95 \\
\hline ETF-25025-N100 & 101.5 & 3.76 & 0.34 & 0.52 & 0.60 & 0.48 & 1.10 & 1.03 & 0.98 \\
\hline ETF-25025-N150 & 100.4 & 4.15 & 0.26 & 0.53 & 0.58 & 0.45 & 1.06 & 0.97 & 0.93 \\
\hline Mean & & & 0.50 & 0.50 & 0.55 & 0.49 & 1.00 & 1.00 & 1.01 \\
\hline $\mathrm{COV}$ & & & 0.37 & 0.06 & 0.08 & 0.06 & 0.08 & 0.05 & 0.06 \\
\hline$\phi_{w}$ & & & 0.27 & 0.46 & 0.49 & 0.45 & 0.90 & 0.92 & 0.93 \\
\hline
\end{tabular}


Table 6: Experimental ultimate loads and comparisons with current and proposed design rules - ITF load case.

\begin{tabular}{|c|c|c|c|c|c|c|c|c|c|}
\hline \multirow[t]{2}{*}{ Specimen } & \multirow[b]{2}{*}{$h / t$} & \multirow[b]{2}{*}{$\begin{array}{l}P_{\text {Exp }} \\
(\mathrm{kN})\end{array}$} & \multirow[b]{2}{*}{$P_{\text {AS1664 }}$} & \multirow[b]{2}{*}{$P_{\mathrm{AS} 4600}$} & \multirow[b]{2}{*}{$P_{\text {Sundararajah }}$} & \multicolumn{4}{|c|}{ Ultimate load ratios (Test/Prediction) } \\
\hline & & & & & & $P_{\text {EC3 }}$ & $\begin{array}{c}P \\
\text { (Prop.) }\end{array}$ & $\begin{array}{l}P_{\text {AS1664 }} \\
\text { (Prop.) }\end{array}$ & $\begin{array}{c}P_{\mathrm{EC} 3} \\
\text { (Prop.) }\end{array}$ \\
\hline ITF-10030-N25 & 31.1 & $21.40 *$ & 1.30 & 1.01 & 0.67 & 0.63 & NA & NA & NA \\
\hline ITF-10030-N50 & 30.8 & 18.57 & 0.98 & 0.79 & 0.56 & 0.54 & 0.98 & 1.01 & 0.90 \\
\hline ITF-10030-N100 & 30.9 & $18.29^{\#}$ & 0.76 & 0.66 & 0.52 & 0.52 & 0.91 & 0.94 & 0.87 \\
\hline ITF-15030-N25 & 48.2 & $18.71 *$ & 1.17 & 0.91 & 0.63 & 0.60 & NA & NA & NA \\
\hline ITF-15030-N50 & 48.3 & 18.29 & 1.01 & 0.82 & 0.59 & 0.58 & 1.06 & 1.08 & 0.98 \\
\hline ITF-15030-N100 & 48.2 & $18.00^{\#}$ & 0.78 & 0.68 & 0.55 & 0.56 & 0.98 & 0.99 & 0.94 \\
\hline ITF-15030-N150 & 48.1 & $18.30^{\#}$ & 0.65 & 0.64 & 0.54 & 0.56 & 0.95 & 0.96 & 0.93 \\
\hline ITF-20025-N25 & 79.0 & $12.82 *$ & 1.12 & 1.02 & 0.67 & 0.66 & NA & NA & NA \\
\hline ITF-20025-N50 & 78.9 & 12.23 & 0.93 & 0.91 & 0.61 & 0.62 & 1.08 & 1.06 & 1.05 \\
\hline ITF-20025-N100 & 79.2 & $12.19^{\#}$ & 0.75 & 0.81 & 0.58 & 0.61 & 1.03 & 1.02 & 1.04 \\
\hline ITF-20025-N150 & 79.2 & $12.27^{\#}$ & 0.60 & 0.66 & 0.55 & 0.59 & 0.97 & 0.94 & 1.00 \\
\hline ITF-20030-N25 & 65.9 & $18.12 *$ & 1.10 & 0.82 & 0.63 & 0.61 & NA & NA & NA \\
\hline ITF-20030-N50 & 65.3 & 18.00 & 0.95 & 0.76 & 0.60 & 0.59 & 1.05 & 1.06 & 1.00 \\
\hline ITF-20030-N100 & 65.9 & $17.59^{\#}$ & 0.75 & 0.66 & 0.56 & 0.58 & 1.00 & 1.00 & 0.98 \\
\hline ITF-20030-N150 & 66.3 & $17.62^{\#}$ & 0.62 & 0.59 & 0.54 & 0.57 & 0.96 & 0.94 & 0.97 \\
\hline ITF-25025-N25 & 101.3 & $12.08^{*}$ & 1.03 & 0.89 & 0.66 & 0.67 & NA & NA & NA \\
\hline ITF-25025-N50 & 101.7 & 11.79 & 0.88 & 0.80 & 0.62 & 0.65 & 1.09 & 1.05 & 1.11 \\
\hline ITF-25025-N100 & 101.2 & $11.77^{\#}$ & 0.69 & 0.68 & 0.58 & 0.63 & 1.02 & 0.98 & 1.07 \\
\hline ITF-25025-N150 & 101.3 & $11.91^{\#}$ & 0.58 & 0.62 & 0.56 & 0.62 & 0.98 & 0.94 & 1.06 \\
\hline Mean & & & 0.88 & 0.78 & 0.59 & 0.60 & 1.00 & 1.00 & 0.99 \\
\hline $\mathrm{COV}$ & & & 0.24 & 0.17 & 0.08 & 0.07 & 0.05 & 0.06 & 0.07 \\
\hline$\phi_{w}$ & & & 0.61 & 0.62 & 0.53 & 0.57 & 0.93 & 0.92 & 0.91 \\
\hline
\end{tabular}

* The specimen failed in combined web crippling and flange crushing.

\# The ends of specimen started to deform before reaching the ultimate load. 